\title{
Not So Disconnected: Exchange Rates and the Capital Stock
}

\author{
Tarek A. Hassan \\ University of Chicago, NBER, and CEPR \\ Thomas M. Mertens \\ Federal Reserve Bank of San Francisco \\ Tony Zhang \\ University of Chicago \\ December 2015 \\ Working Paper 2015-21
}

http://www.frbsf.org/economic-research/publications/working-papers/wp2015-21.pdf

\section{Suggested citation:}

Hassan, Tarek A, Thomas M. Mertens, Tony Zhang. 2015. "Not So Disconnected: Exchange Rates and the Capital Stock.” Federal Reserve Bank of San Francisco Working Paper 2015-21. http://www.frbsf.org/economic-research/publications/working-papers/wp2015-21.pdf

The views in this paper are solely the responsibility of the authors and should not be interpreted as reflecting the views of the Federal Reserve Bank of San Francisco or the Board of Governors of the Federal Reserve System. 


\title{
Not So Disconnected:
}

\section{Exchange Rates and the Capital Stock*}

\author{
Tarek A. Hassan ${ }^{\dagger} \quad$ Thomas M. Mertens ${ }^{\ddagger} \quad$ Tony Zhang§
}

December 2015

\begin{abstract}
We investigate the link between stochastic properties of exchange rates and differences in capital-output ratios across industrialized countries. To this end, we endogenize capital accumulation within a standard model of exchange rate determination with nontraded goods. The model predicts that currencies of countries that are more systemic for the world economy (countries that face particularly volatile shocks or account for a large share of world GDP) appreciate when the price of traded goods in world markets is high. These currencies are better hedges against consumption risk faced by international investors because they appreciate in "bad" states of the world. As a consequence, more systemic countries face a lower cost of capital and accumulate more capital per worker. We estimate our model using data from seven industrialized countries with freely floating exchange rate regimes between 1984 and 2010 and show that cross-country variation in the stochastic properties of exchange rates accounts for $72 \%$ of the cross-country variation in capital-output ratios. In this sense, the stochastic properties of exchange rates map to fundamentals in the way predicted by the model.
\end{abstract}

JEL classification: F3, G0

Keywords: exchange rate disconnect, capital accumulation, international capital flows

* Prepared for the International Seminar on Macroeconomics 2015. We thank Charles Engel, Luca Fornaro, Tommaso Monacelli, Brent Neiman, Anna Pavlova, Hélène Rey, and Robert Richmond for helpful comments. Hassan is grateful to the Fama-Miller Center at the University of Chicago for providing financial support. The views expressed here are solely those of the authors and do not necessarily represent those of the Federal Reserve Bank of San Francisco or the Federal Reserve System.

${ }^{\dagger}$ University of Chicago, NBER, and CEPR; Postal Address: 5807 S Woodlawn Avenue, Chicago IL 60637 , USA; E-mail: tarek.hassan@chicagobooth.edu.

${ }^{\ddagger}$ Federal Reserve Bank of San Francisco; Postal Address: 101 Market Street Mail Stop 1130, San Francisco, CA 94105, USA; E-mail: thomas.mertens@sf.frb.org.

$\S$ University of Chicago; Postal Address: 5807 S Woodlawn Avenue, Chicago IL 60637, USA; E-mail: tony.wtz@gmail.com. 


\section{Introduction}

A large literature links variation in capital-output ratios across countries to differences in the cost of capital and technology. Such differences have been attributed to heterogeneity in the protection of property rights (Hall and Jones, 1997), taxation rates (Jorgenson, 1996), depreciation rates, the capital share of output (Karabarbounis and Neiman, 2014), and distortions in the allocation of resources (Hsieh and Klenow, 2009). In this paper, we argue that differences in the stochastic properties of countries' real exchange rates may be another important driver of variation in capital-output ratios across countries.

If firms are price-takers and use a Cobb-Douglas production technology, we can summarize the various drivers of heterogeneity across countries in capital-output ratios by equating the expected marginal product of capital to its marginal cost and writing

$$
\mathbb{E}\left(Y_{i} / K_{i}\right)=\frac{\left(\mathbb{E}\left[\tilde{r}_{i}\right]+\delta_{i}\right) \tau_{i}}{\nu_{i}}
$$

where $\mathbb{E}\left(Y_{i} / K_{i}\right)$ is the expected output per unit of capital installed in country $i, \delta_{i}$ is the depreciation rate, $\nu_{i}$ is the capital share of output, and $\tau_{i}$ summarizes distortions that may be caused by variation in tax rates, the protection of property rights, or dysfunctional markets. In contrast to these well-established factors, cross-country variation in the required net rate of return to capital, $\mathbb{E}\left[\tilde{r}_{i}\right]$, has received relatively little attention as a potential driver of differences in capital accumulation across countries.

Nevertheless, there are good reasons to believe that $\mathbb{E}\left[\tilde{r}_{i}\right]$ varies systematically across countries. The required rate of return to capital installed in a given country consists of two parts, the country's risk-free rate of interest and a risk premium. A growing literature in international asset pricing argues that heterogeneity in the stochastic properties of countries' real exchange rates generates differences in the former. In particular, a common theme in this literature is that countries whose currencies tend to appreciate in "bad" times have lower risk-free interest rates (Hassan, 2013, Martin, 2012) and pay lower expected returns (Lustig and Verdelhan, 2007).

In this paper, we endogenize capital accumulation within a canonical model of exchange rate determination and show that countries whose currencies appreciate when 
the shadow price of traded goods is high also have a lower required rate of return to capital installed in their nontraded sectors. As a result, these countries install higher capital-output ratios in equilibrium. When we calibrate our model to match data for seven OECD countries with freely-floating exchange rates, we find that heterogeneity in the stochastic properties of their exchange rates can account for $72 \%$ of the variation in their relative capital-output ratios.

Our model builds on the canonical model of exchange rate determination: households consume a bundle of a freely traded good and a country-specific nontraded good. The nontraded good is produced using capital and labor as inputs, subject to a country-specific productivity shock. This productivity shock induces variation in output of nontraded goods that allows the consumption price index to differ across countries and, as a result, induces variation in the real exchange rate. In addition, country-specific shocks to the inflation rate affect real exchange rates because a subset of households can only hold nominal bonds that make fixed payments in terms of the currency of the country in which they reside. The remaining households have access to complete international asset markets. In equilibrium, the real exchange rate thus responds to (real) shocks to the productivity in production of nontraded goods across countries and to (monetary) shocks to the inflation rates of national currencies.

Our most important addition to this canonical setup is heterogeneity across countries in volatility and size: some countries are affected by more volatile productivity or inflation shocks than others and some countries account for a larger share of world GDP than others (they comprise more or wealthier households).

Heterogeneity in volatility and size generates differences in the stochastic properties of countries' exchange rates. First, countries that experience more volatile productivity and inflation shocks tend to have more volatile exchange rates. Second, the currencies of larger and more volatile countries tend to appreciate in "bad" times: households react to shocks by shipping traded goods across countries in an effort to share risk across borders. However, the shocks that affect larger or more volatile countries (for ease of reference, we refer to them as more "systemic" countries) are harder to diversify internationally. For example, when a country has a low per capita output of nontraded goods, its nontraded good becomes relatively more expensive and its real exchange rate appreciates. To com- 
pensate for the shortfall of nontraded goods the country imports additional traded goods from the rest of the world. However, a low output of nontraded goods in a large country simultaneously triggers a rise in the world market price of traded goods, while a low output of nontraded goods in a small country does not. As a consequence, the currencies of more systemic countries tend to appreciate when the world market price of traded goods is high.

These differences in the stochastic properties of real exchange rates in turn are indicative of differential incentives for capital accumulation. Households around the world worry about states of the world in which more systemic countries suffer bad productivity shocks because these shocks are transmitted to the rest of the world in the form of higher prices of traded goods. Although households cannot prevent these states from occurring, they can partially insure against them by accumulating more capital and thus raising the mean level of output of nontraded goods in systemic countries across all states. Accumulating more capital in the nontraded sector of more systemic countries thus softens the impact of adverse shocks in these countries and represents a good hedge against world-wide consumption risk. In other words, large countries and countries with volatile exchange rates have a low required rate of return on capital in the nontraded sector and attract investment because they have "safe" currencies that appreciate in "bad" times.

As documented in earlier work (Hassan, 2013), this insurance property of the currencies of systemic countries also allows the model to match a number of stylized facts documented in the recent empirical literature on international asset prices: (i) countries that are either large or have more volatile nontraded sectors have lower risk-free and nominal interest rates, (ii) stocks in the nontraded sector of larger countries pay lower expected returns, (iii) high interest rate currencies tend to depreciate when US consumption growth is low, and (iv) a portfolio that is long high interest rate currencies and short low interest rate currencies is a priced factor in international currency markets (Lustig and Verdelhan, 2007; Lustig et al., 2011; Hassan, 2013; Tran, 2013). Our main theoretical contribution is thus to show that these predictions about cross-currency variation in asset returns also produce differential incentives for capital accumulation across countries.

An important detail in the predictions of our model is that the link between capital accumulation and stochastic properties of exchange rates is specific to the nontraded 
sector and does not affect the incentive to accumulate capital for the purposes of the production of traded goods. The reason is that shocks affecting the traded sector are fully shared internationally and thus have no effect on the relative price of consumption in different countries nor on real exchange rates. As a result, the stochastic properties of exchange rates have implications for cross-country variation in the incentive to accumulate capital only in the nontraded but not in the traded sector. In the interest of parsimony we therefore abstract from capital accumulation in the traded sector throughout our analysis.

In addition to deriving these qualitative results, we take several steps to make the model quantitatively viable and take it to the data. To this end, we first show formally that the conclusions outlined above hold regardless of whether markets are complete or incomplete, and regardless of whether variation in exchange rates is driven by real or monetary shocks. This finding is particularly important because allowing for market incompleteness significantly improves the model's fit to the data. One long-standing challenge for models of exchange rate determination with complete markets is that they predict a perfect, negative correlation between appreciations of the real exchange rate and consumption growth (this is the seminal Backus and Smith (1993) puzzle). By contrast, inflation shocks induce a positive correlation between appreciations and consumption growth when markets are incomplete. Allowing for market incompleteness and both real and monetary shocks can thus generate a correlation between appreciations and differential consumption growth that is more consistent with the data. Moreover, allowing for market incompleteness increases the effect of a given productivity shock on the real exchange rate and raises its volatility in equilibrium, partially addressing another welldocumented shortcoming of the complete-markets model.

We calibrate our model using data from seven industrialized countries that maintain freely floating exchange rates during the sample period, 1984-2010. Rabanal and RubioRamirez (2015) argue that the model performs well even with standard preferences when considering the volatility of real exchange rates over the entire frequency domain rather than focusing only on business-cycle frequencies. However, to get more precise estimates of stochastic properties of exchange rates and for comparison with the majority of the existing literature, we use annual data in our estimation. Our analysis proceeds in three steps. First, we allow countries to differ only in size, measuring each country's size as the 
average share it contributes to the overall GDP of the seven countries under consideration during the sample period. We then estimate the variance of productivity and inflation shocks to match the average variance across countries of GDP growth and consumer price index (CPI) inflation, constraining the variances of the two shocks to be equal across countries. Under this specification, the model accounts for $7 \%$ of the variation in crosscountry differences in capital-output ratios.

In a second step, we repeat the same procedure but now allow heteroskedastic productivity and inflation shocks across countries: We estimate the relative size of each country's shocks to match the variance of its equal-weighted average real and nominal exchange rates, subject to the constraint that we again match the average variance across countries of GDP growth and CPI inflation. This heteroskedastic specification accounts for $72 \%$ of the variation in cross-country differences in capital-output ratios. In this sense, the stochastic properties of exchange rates, as proxied by differences in country size and the variances of exchange rates, can account for the majority of the differences in capitaloutput ratios across the seven countries in our sample. At the same time, the model produces a small negative correlation between appreciations and consumption growth and thus is not obviously rejected by the data along this dimension.

Although the baseline model does remarkably well in predicting the relative differences in capital-output ratios across countries, it fails dramatically on magnitudes. For example, in the data, Canada has a 30\% lower capital-output ratio than the United States whereas the model predicts a difference of around $0.03 \%$. Similarly, although the model (by construction) matches the relative variances of the real exchange rate, it under-predicts the average variance of real exchange rates as well as the equity premium. We thus conjecture that the model's failure to match the quantitative magnitude of the differences in capital-output ratios may be related to the well-known failure of the canonical model to generate sufficiently large risk premia and sufficiently large variability of the real exchange rate.

In a third step, we apply a series of modifications to the model that address the latter issue, including the introduction of capital adjustment costs. The general pattern we find is that, consistent with our conjecture, modifications that increase the variance of the real exchange rate also tend to narrow the gap in magnitudes, although no single modification 
yields entirely satisfactory results.

A branch of the literature in international finance has had some success in matching these facts while preserving the complete-markets framework. For example, Colacito and Croce (2011) get a good fit to the data when combining highly persistent shocks to productivity with Epstein and Zin (1989) preferences. Alternatively, matching the entire frequency domain rather than just the annual variation in exchange rates can help in matching quantities in the model (Rabanal and Rubio-Ramirez (2015)). Both are promising alternative approaches to improving the model's fit to the data and quantifying the mechanism described in this paper.

The conclusion of our analysis is that the stochastic properties of countries' exchange rates contain information that may account for some of the large variation in capitaloutput ratios across countries. We make two main caveats to this interpretation. First, our results are based on a sample of relatively homogeneous developed countries that have similar institutions, tax systems, and well-functioning markets. This relative homogeneity may explain why we get a good fit to the data even without controlling for these other factors. In a sample comprised of a broader set of countries, especially developed and developing countries, we would expect the stochastic properties of exchange rates to play a relatively smaller role in explaining differences in capital-output ratios. Therefore, we make no claim about the importance of heterogeneity in stochastic properties of countries' real exchange rates relative to heterogeneity in these other factors. Second, our baseline model matches only relative differences, but falls far from the mark in matching the magnitude of absolute differences. For this reason, our empirical results should be interpreted with due caution.

An additional limitation of our empirical work is that, due to a lack of comparable data, we only measure differences in capital-output ratios for the economy as a whole rather than specifically for the nontraded sector. However, we do not believe that this is a particularly problematic shortcoming as nontraded goods account for a large share of GDP.

Our work relates to a growing theoretical literature that centers on the idea that currencies that appreciate in "bad" times pay lower returns and have lower risk-free interest 
rates in equilibrium. This literature has explored various potential drivers of heterogeneity of the stochastic properties of countries' real exchange rates, including differences in country size (Hassan, 2013; Martin, 2012; Govillot, Rey, and Gourinchas, 2010), the size and volatility of shocks affecting the nontraded sector (Tran, 2013), financial development (Maggiori, 2013), and patterns of production specialization (Ready, Roussanov, and Ward, 2013; Richmond, 2015). We contribute to this literature by showing that the same forces that generate differences in currency returns also generate differences in the incentive to accumulate capital across countries, which links this literature to the broader literature on differences in factor accumulation across countries. 1

Our paper also relates to a parallel empirical literature that shows evidence that is broadly consistent with the predictions of these models, including Lustig and Verdelhan (2007), Campbell, Serfaty-De Medeiros, and Viceira (2010), Menkhoff, Sarno, Schmeling, and Schrimpf (2012), Lustig, Roussanov, and Verdelhan (2011), and David, Henriksen, and Simonovska (2014) $)^{2}$ Our contribution to this empirical literature is to show that information contained in the variance-covariance matrix of exchange rates can predict differences in capital accumulation between the seven industrialized countries in our sample.

Finally, our work also relates to the broader literature on violations of uncovered interest parity by arguing that persistent violations of uncovered interest parity have real effects on factor accumulation. For an overview of this literature see the surveys by Lewis (2011), and Engel (2014), as well as Hassan and Mano (2014).

The remainder of this paper is structured as follows: Section 2 sets up and derives the equilibrium conditions of the model. Section 3 derives the main economic insights using a special case of the model with two periods, full depreciation, and Cobb-Douglas utility. Section 4 solves and estimates the fully dynamic model. Section 5 concludes.

\footnotetext{
${ }^{1}$ In this sense our paper also relates to the literature studying the effects of the exchange rate regime and monetary stabilization on factor accumulation, net foreign asset positions, and entry. Examples include Kollmann (2002), Fornaro (2015), and Bergin and Corsetti (2015).

${ }^{2}$ Also see the evidence in some of the aforementioned papers, including Hassan (2013), Tran (2013), and Ready, Roussanov, and Ward (2013) and Richmond (2015).
} 


\section{A Model of Exchange Rates and Capital Accumu- lation}

In this section, we develop an international asset pricing model in which the allocation of capital across countries and the stochastic properties of real exchange rates are jointly determined as a function of real and monetary shocks. The model generalizes the framework in Hassan (2013) by introducing a fully dynamic setting and endogenizing the accumulation of capital in the nontraded sector. It nests the canonical complete-markets of exchange rate determination (Backus and Smith, 1993) as well as a simplified version of the incomplete-markets model by Alvarez, Atkeson, and Kehoe (2002) $3^{3}$ Closely related to our framework are Devereux, Smith, and Yetman (2009) and Kollmann (2012) who also combine elements of the canonical complete-markets setup with a form of within-country market segmentation, but do not consider heterogeneous countries or endogenous capital accumulation.

\section{$2.1 \quad$ Setup}

There exists a unit measure of households $i \in[0,1]$, partitioned into $N$ subsets $\Theta^{n}$ of measure $\theta^{n}, n=1, \ldots, N$. Each subset represents the constituent households of a country $n$. Households' utility functions exhibit constant relative risk aversion according to

$$
U(i)=\sum_{t=0}^{T} \frac{\beta^{t}}{1-\gamma} \mathbb{E}\left[C_{t}(i)^{1-\gamma}\right]
$$

where $\beta$ is the time discount factor, $C_{t}(i)$ is the quantity of a final good consumed by household $i$ at time $t$, and $T$ is a terminal period (equal to 1 and $\infty$ in sections 3 and 4. respectively). Households are risk-averse with $\gamma>0$. The final good can be used for consumption or investment in capital. Households produce the final good using a traded

\footnotetext{
${ }^{3}$ Similar models of exchange rate determination with complete markets and nontraded goods include Stockman and Dellas (1989), Tesar (1993), Stockman and Tesar (1995), Baxter, Jermann, and King (1998), and Collard, Dellas, Diba, and Stockman (2007).
} 
and a nontraded (intermediate) good according to

$$
Y_{t}(i)=\left[\tau I_{T, t}(i)^{\alpha}+(1-\tau) I_{N, t}(i)^{\alpha}\right]^{\frac{1}{\alpha}},
$$

where $\tau \in(0,1)$ is the weight of the traded good in the production function, $I_{T, t}(i)$ is the number of traded goods used as inputs by household $i, I_{N, t}(i)$ is the number of nontraded goods used, and $\alpha \in(0,1)$ determines the elasticity of substitution between the two inputs, $\varepsilon_{\alpha}=1 /(1-\alpha)$. Once produced, the final good is freely traded among all households within a given country.

At the start of each period, households receive a stochastic endowment of the homogenous traded good. Shocks to endowments are common within each country such that all households within a country $n$ receive the same amount $Y_{T, t}^{n}$ of the traded good with

$$
\log \left[Y_{T, t}^{n}\right] \sim N\left(0, \sigma_{T, n}^{2}\right) .
$$

Throughout, we use the traded good as the numéraire, such that all prices and returns are accounted for in the same units.

In each country, a representative firm operates a technology for producing nontraded goods employing capital and labor as inputs. Each household inelastically supplies one unit of labor. The per capita output of nontraded goods is equal to

$$
Y_{N, t}^{n}=\exp \left[\eta_{t}^{n}\right]\left(K_{t}^{n}\right)^{\nu}
$$

where $0<\nu<1$ is the capital share in production, $K_{t}^{n}$ is the per capita stock of capital in country $n$, and $\eta_{t}^{n}$ is a productivity shock to the production of non-tradable goods in period $t$,

$$
\eta_{t}^{n} \sim N\left(0, \sigma_{N, n}^{2}\right) .
$$

The law of motion for per capita capital is

$$
K_{t+1}^{n}=(1-\delta) K_{t}^{n}+I_{K, t},
$$

where $\delta$ is the depreciation rate of capital and $I_{K, t}$ is the per capita level of investment in 
period $t$. Goods cannot be stored and must be consumed or invested in the period they are produced or endowed.

A fixed proportion $\phi$ of households within each country own equal shares of the representative firm in their country and trade a complete set of state-contingent securities across all time periods in international markets. We label these households as "active."

The remaining proportion $1-\phi$ of households within each country is excluded from owning stocks or trading state-contingent securities. We label these households as financially "inactive." Inactive households cede the claims to their endowments and wages in each period $t$ to their country's active households and receive a nominal bond in return. This nominal bond pays off a fixed number of units of the country's nominal consumer price index in the following period $(t+1)$. In each period, each inactive household thus receives a payment of $P_{t}^{n} e^{-\mu_{t}^{n}} C_{s s}$ traded goods, where $P_{t}^{n}$ is the number of traded goods required to purchase one real unit of country $n$ 's final good in period $t, \mu_{t}^{n}$ is an exogenous inflation shock to the nominal price of one unit of the traded good in terms of the currency of country $n$,

$$
\mu_{t}^{n} \sim N\left(0, \tilde{\sigma}_{n}^{2}\right),
$$

and $C_{s s}$ is a normalizing constant that equalizes consumption between active and inactive households at the deterministic steady state.

To simplify notation, let $\omega$ represent the state vector, recording the realization of endowments, inflation shocks, and capital stocks across countries within a given period. In what follows, we indicate the dependence on the state once for each variable and drop the argument thereafter whenever appropriate.

All households take prices as given. Active households maximize their lifetime utility (1) subject to their intertemporal budget constraint

$$
\begin{aligned}
& \sum_{t=0}^{T}\left[\int_{\omega} Q_{t}(\omega)\left(P_{t}^{n}(\omega) C_{t}(i, \omega)+\frac{1-\phi}{\phi} P_{t}^{n}(\omega) e^{-\mu_{t}^{n}} C_{s s}\right) d \omega\right] \\
\leq & \sum_{t=0}^{T}\left[\int_{\omega} Q_{t}(\omega) \frac{1}{\phi}\left(Y_{T, t}^{n}(\omega)+w_{t}^{n}(\omega)+\pi_{t}^{n}(\omega)\right) d \omega\right]+\kappa^{n},
\end{aligned}
$$

where $Q_{t}(\omega)$ is the time-zero price of a state contingent security that pays one unit of 
the tradable good in period $t$ if state $\omega$ occurs, $P_{t}^{n}(\omega)$ denotes the price of country $n$ 's final good in period $t, w_{t}^{n}(\omega)$ is the wage rate and $\pi_{t}^{n}(\omega)$ is the per capita share of profits accruing to the country's representative firm. Note that $\frac{1-\phi}{\phi}$ is the number of inactive households per active household in each country. To simplify the solution of the model, we also assume that active households receive a country-specific transfer $\kappa^{n}$ before trading begins such that the decentralized problem coincides with the Social Planner's allocation with unit Pareto weights. We therefore do not consider the effects that asymmetries in the stochastic properties of exchange rates may have on the distribution of initial wealth across countries.

Inactive households also maximize (1), but subject to the constraints

$$
P_{t}^{n}(\omega) \hat{C}_{t}(i, \omega) \leq P_{t}^{n}(\omega) e^{-\mu_{t}^{n}} C_{s s} \forall n, t
$$

where $\hat{C}_{t}(i, \omega)$ is the consumption of final goods by inactive household $i$. Since inactive households cannot transfer goods across periods, they optimally choose to consume the entire payment received from their nominal bond, and thus

$$
\hat{C}_{t}(i)=\hat{C}_{t}^{n}=e^{-\mu_{t}^{n}} C_{s s} \quad \forall i \in \Theta^{n} .
$$

Each country's representative firm makes investment decisions to maximize its present discounted value of future profits, $\pi_{t}^{n}$, subject to the law of motion for capital (4). The firm's objective function is

$$
\max _{\left\{I_{K, t}^{n}(\omega)\right\}_{t}} \sum_{t=0}^{T} \int_{\omega} Q_{t}(\omega) \theta^{n}\left(P_{N, t}^{n}(\omega) Y_{N, t}^{n}(\omega)-w_{t}^{n}(\omega)-P_{t}^{n}(\omega) I_{K, t}^{n}(\omega)\right) d \omega
$$

where $P_{N, t}^{n}$ is the price of country $n$ 's nontraded good.

The market clearing conditions for final, nontraded, and traded goods within a given period $t$ are

$$
\begin{gathered}
\int_{i \in \Theta^{n}} C_{t}(i, \omega) d i+\theta^{n} I_{K, t}^{n}(\omega)=\int_{i \in \Theta^{n}} Y_{t}(i, \omega) d i \quad \forall n, \\
\int_{i \in \Theta^{n}} I_{N, t}(i, \omega) d i=\theta^{n} Y_{N, t}^{n}(\omega) \quad \forall n,
\end{gathered}
$$


and

$$
\int_{i \in \Theta^{n}} I_{T, t}(i, \omega) d i=\sum_{n} \theta^{n} Y_{T, t}^{n}(\omega)
$$

respectively. The economy is at an equilibrium when all households maximize utility subject to their budget constraints, firms maximize the present discounted value of profits subject to the law of motion of capital, and goods markets clear.

\subsection{Solving the Model}

Although financial markets are incomplete, the model's solution remains tractable because a subset of the population in each country (active households) have access to complete markets. As a result, we can solve for the equilibrium allocation of capital and goods by solving the Social Planner's problem, subject to the equilibrium behavior of inactive households. To characterize this behavior, it is useful to calculate the number of inputs of traded and nontraded goods used for the production of final goods consumed by each inactive household according to (7). Taking prices as given, inactive households use the optimal mix of traded and nontraded goods given by

$$
\hat{I}_{T, t}^{n}=\frac{\exp \left(-\mu_{t}^{n}\right) P_{t}^{n} C_{s s}}{1+\left[\frac{\tau}{1-\tau}\left(P_{N, t}^{n}\right)^{\alpha}\right]^{\frac{1}{\alpha-1}}}, \hat{I}_{N, t}^{n}=\frac{\left[\frac{\tau}{1-\tau}\left(P_{N, t}^{n}\right)\right]^{\frac{1}{\alpha-1}} \exp \left(-\mu_{t}^{n}\right) P_{t}^{n} C_{s s}}{1+\left[\frac{\tau}{1-\tau}\left(P_{N, t}^{n}\right)^{\alpha}\right]^{\frac{1}{\alpha-1}}}
$$

where $\hat{I}_{T}^{n}$ and $\hat{I}_{N}^{n}$ refer to the inputs of traded and nontraded goods used by inactive households in country $n$, respectively $4^{4}$

All active households within a given country are identical and receive the same endowments. In a symmetric equilibrium, they consume the same number of final goods $C_{t}^{n}$, and use the same number of traded and nontraded goods inputs $\left(I_{T, t}^{n}, I_{N, t}^{n}\right)$. Using this simplified notation, we can write the Social Planner's problem as

$$
V\left(K_{t}^{n}, Y_{T, t}^{n}, \eta_{t}^{n}, \mu_{t}^{n}\right)=\max _{\left\{I_{T, t}^{n}, I_{N, t}^{n}, I_{K, t}^{n}\right\}_{n, t}} \sum_{n} \phi \theta^{n} \frac{\left(C_{t}^{n}\right)^{1-\gamma}}{1-\gamma}+\beta \mathbb{E}\left[V\left(K_{t+1}^{n}, Y_{T, t+1}^{n}, \eta_{t+1}^{n}, \mu_{t+1}^{n}\right)\right]
$$

subject to 12 as well as the economy's resource constraints for final goods, nontraded

\footnotetext{
${ }^{4}$ See Appendix $\mathrm{A}$ for a formal proof.
} 
goods, and traded goods $5^{5}$

For further reference, we denote the Lagrange multipliers on these $2 n+1$ resource constraints as $\Lambda_{t}^{n}, \Lambda_{N, t}^{n}$, and $\Lambda_{T, t}$ and interpret them as the Social Planner's shadow prices of final, nontraded, and traded goods, respectively. Given this definition, we can re-write the prices in $(12)$ as

$$
P_{N, t}^{n}(\omega)=\frac{\Lambda_{N, t}^{n}(\omega)}{\Lambda_{T, t}(\omega)} \text { and } P_{t}^{n}(\omega)=\frac{\Lambda_{t}^{n}(\omega)}{\Lambda_{T, t}(\omega)}
$$

completing the setup of the Social Planner's problem.

The first-order conditions with respect to $I_{T, t}^{n}$ equate the shadow price of the traded good across all active households in the world,

$$
\tau\left(I_{T, t}^{n}\right)^{\alpha-1}\left(\tau\left(I_{T, t}^{n}\right)^{\alpha}+(1-\tau)\left(I_{N, t}^{n}\right)^{\alpha}\right)^{\frac{1}{\alpha}-1}\left(C_{t}^{n}\right)^{-\gamma}=\Lambda_{T, t} \forall n
$$

The first-order conditions with respect to $I_{N, t}^{n}$ define the shadow prices of nontraded goods within each country,

$$
(1-\tau)\left(I_{N, t}^{n}\right)^{\alpha-1}\left(\tau\left(I_{T, t}^{n}\right)^{\alpha}+(1-\tau)\left(I_{N, t}^{n}\right)^{\alpha}\right)^{\frac{1}{\alpha}-1}\left(C_{t}^{n}\right)^{-\gamma}=\Lambda_{N, t}^{n} \forall n
$$

In addition, it is useful to keep track of the (redundant) first-order condition with respect to $C_{t}^{n}$ because it pins down the marginal utility of consumption of active households in each country,

$$
\left(C_{t}^{n}\right)^{-\gamma}=\Lambda_{t}^{n} \forall n
$$

By definition, the real exchange rate between two countries $h$ and $f$ equals the ratio of these shadow prices,

$$
S_{t}^{f, h}(\omega)=\Lambda_{t}^{f}(\omega) / \Lambda_{t}^{h}(\omega)
$$

Finally, combining the first-order conditions with respect to $I_{K, t}^{n}$ with the corresponding envelope conditions yields an Euler equation for the accumulation of capital in each

\footnotetext{
${ }^{5}$ See Appendix $\mathrm{B}$ for the derivation of these constraints.
} 
country,

$$
\left(C_{t}^{n}\right)^{-\gamma}=\beta \mathbb{E}\left[(1-\delta)\left(C_{t+1}^{n}\right)^{-\gamma}+\Lambda_{N, t+1}^{n} \exp \left[\eta_{t+1}^{n}\right] \nu\left(K_{t+1}^{n}\right)^{\nu-1}\right] \quad \forall n
$$

Combining these $N$ Euler equations with the $3 N$ resource constraints and the $3 N$ firstorder conditions (14) - (16) yields a recursive system of $7 N$ equations that determines the sequence of endogenous variables $\left\{I_{T, t}^{n}, I_{N, t}^{n}, C_{t}^{n}, K_{t+1}^{n}, \Lambda_{t}^{n}, \Lambda_{N, t}^{n}, \Lambda_{T, t}\right\}_{n, t}$.

\section{Exchange Rates and the Capital Stock}

From (17), it is already apparent that heterogeneity in the effect of the country-specific productivity shock $\eta_{t+1}^{n}$ on the shadow value of nontraded goods $\left(\Lambda_{N, t+1}^{n}\right)$ induces variation in the incentive to accumulate capital across countries. To illustrate how such heterogeneity relates to heterogeneity in the stochastic properties of countries' real exchange rates, we first consider a simplified, two-period version of the model. In this simplified version, the production technology for final goods is Cobb-Douglas $\left(\varepsilon_{\alpha}=1\right)$, capital fully depreciates between periods $(\delta=1)$, the economy is at its deterministic steady state at $t=0$, and the world ends at $T=1$. In this case, (17) simplifies to

$$
K_{1}^{n}=\beta \frac{\nu}{\left(C_{0}^{n}\right)^{-\gamma}} \mathbb{E}\left[\Lambda_{N, 1}^{n} Y_{N, 1}^{n}\right]
$$

Moreover, from 15, 16 , and 32 , it follows that $\Lambda_{N, 1}^{n} Y_{N, 1}^{n}=(1-\tau)\left(\Lambda_{1}^{n}\right)^{1-\frac{1}{\gamma}}$. Guessing that all endogenous variables are log-normally distributed in equilibrium, we can then write the difference in two countries' per capita stocks as

$$
k_{1}^{f}-k_{1}^{h}=\frac{\gamma-1}{\gamma} \mathbb{E}\left(\lambda_{1}^{f}-\lambda_{1}^{h}-\left(\lambda_{0}^{f}-\lambda_{0}^{h}\right)\right)+\frac{1}{2}\left(\frac{\gamma-1}{\gamma}\right)^{2}\left(\operatorname{var}\left(\lambda_{1}^{f}\right)-\operatorname{var}\left(\lambda_{1}^{h}\right)\right),
$$

where lowercase variables stand for $\operatorname{logs}$ such that $x=\log (X)$. This equation shows that differences in capital accumulation between countries are a function of expected changes in the real exchange rate between the two countries (the first term on the right hand side) and of the difference in the variance of the marginal utility of consumption in the two 
countries (the second term). Plainly, both terms reflect stochastic properties of the real exchange rate between the two countries, $s_{t}^{f, h}=\lambda_{t}^{f}-\lambda_{t}^{h}{ }^{6}$

Because the economy is at its deterministic steady-state in $t=0$, cross-country differences in the first term on the right-hand side of (18) can only arise as a result of differences in the second term. Put differently, the only reason for expected growth of marginal utilities to differ across countries is if households in these countries accumulate different levels of capital for use in period 1. The first term thus represents a feedback effect that operates only if the second term is non-zero. The key driver of cross-country differences in capital accumulation is therefore the difference in the variance of the marginal utility of consumption of active households across countries.

To study this term in closed form, we log-linearize the model around the deterministic steady state, i.e., the point at which the variances of all shocks are zero $\left(\sigma_{T, n}, \sigma_{N, n}, \tilde{\sigma}_{n}=0 \forall n\right)$ and all households have a capital stock that is fixed at the deterministic steady state level. That is, for the remainder of this section, we study the incentives to accumulate different levels of capital across countries while holding the capital stock fixed. Appendix C shows the log-linearized system of equations.

We proceed in three steps. The following subsection studies the effect of productivity shocks on the stochastic properties of exchange rates and capital accumulation by considering the special case in which financial markets are complete $\phi=1$. We then consider the effect of inflation shocks while abstracting from productivity shocks before combining the insights from both special cases and discussing the joint effects of real and monetary shocks.

\subsection{Real Shocks, Exchange Rates, and the Capital Stock}

Equation (19) shows the equilibrium use of the traded good in an arbitrary country $h$ for the special case in which financial markets are complete, $\phi=1$ (recall that lowercase

\footnotetext{
${ }^{6}$ Note that this condition is also closely related to very similar conditions that relate cross-country differences in expected currency returns to cross-country differences in the variances of stochastic discount factors, as in Backus, Foresi, and Telmer (2001). We discuss this analogy in detail in section 3.3
} 
variables stand for logs):

$$
i_{T}^{h}=\bar{y}_{T}+\frac{(\gamma-1)(1-\tau)}{(1-\tau)+\tau \gamma}\left(\bar{y}_{N}-y_{N}^{h}\right)
$$

where $\bar{y}_{N}=\sum_{n=1}^{N} \theta^{n} y_{N}^{n}$ is the average of the log output of non-tradables across countries and $\bar{y}_{T}=\sum_{n=1}^{N} \theta^{n} y_{T}^{n}$ is the average of the log world endowment of tradables. As one may expect, use of the traded good in the home country moves one for one with the world supply. Since the traded good can be freely shipped around the globe, it is inconsequential which country has a better or worse endowment of tradables, as long as $\bar{y}_{T}$ is constant. Households thus perfectly share risk when it comes to endowments of the traded good. However, the second term of (19) shows that they also use the traded good to insure against productivity shocks in the nontraded sector. Although non-tradables cannot be shipped, households purchase insurance in world markets in the form of compensating deliveries of traded goods if $\gamma>1$.

This condition ensures that the cross-partial of the shadow price of the traded good with respect to the nontraded good is negative, i.e., that the relative price of a country's nontraded good falls when its supply increases. As most empirical applications of international asset pricing models find a relative risk aversion significantly larger than one, we follow the literature in assuming that this condition is met, but refer to it whenever it is relevant (see Coeurdacier (2009) for a detailed discussion). If relative risk aversion is sufficiently high, households in the home country thus receive additional tradables whenever they have a lower than average output of nontraded goods.

This risk-sharing behavior is reflected in the shadow price of traded goods,

$$
\lambda_{T}=-((1-\tau)+\tau \gamma) \sum_{n=1}^{N} \theta^{n} y_{T}^{n}-(1-\tau)(\gamma-1) \sum_{n=1}^{N} \theta^{n} y_{N}^{n}+\log (\tau)
$$

The first term on the right-hand side shows that the shadow price unambiguously falls with the world supply of traded goods. The second term states that the same is true for the average output of nontraded goods, as long as $\gamma>1$. Thus $\lambda_{T}$ tends to be low in "good" states of the world when endowments of traded goods are high and countries 
experience positive productivity shocks in the nontraded sector 7 Note, however, that not every productivity shock has the same influence on $\lambda_{T}$. Shocks to the productivity of larger countries affect a larger measure of households and thus have a larger effect on $\lambda_{T}$. Similarly, countries with more volatile shocks have a larger impact on the variability of $\lambda_{T}$. The following definition formalizes the notion of large and volatile countries:

\section{Definition 3.1}

Country $f$ is larger than country $h$ if $\theta^{f}>\theta^{h}$. It is more volatile than country $h$ if

$$
\sigma_{N, f}>\sigma_{N, h} \text { and } \tilde{\sigma}_{f}>\tilde{\sigma}_{h}
$$

and it is more systemic than country $h$ if

$$
\theta^{f} \geq \theta^{h} \text { and } \sigma_{N, f} \geq \sigma_{N, h} \text { and } \tilde{\sigma}_{f} \geq \tilde{\sigma}_{h}
$$

with two of the three weak inequalities holding strictly.

The real exchange rate between countries $f$ and $h$ is

$$
s^{f, h}=\lambda^{f}-\lambda^{h}=\frac{\gamma(1-\tau)}{(1-\tau)+\gamma \tau}\left(y_{N}^{h}-y_{N}^{f}\right) .
$$

It depends only on the difference between the per capita production of nontraded goods between the two countries. The country with the lower per-capita output of nontraded goods appreciates.

From inspecting (20) and (21), we can see that the model produces two kinds of heterogeneity in the stochastic properties of countries' exchange rates. First, more volatile countries - that is, countries that experience more volatile productivity shocks - tend to have more volatile exchange rates,

$$
\operatorname{var}\left(s^{f, h}\right)=\left(\frac{\gamma(1-\tau)}{(1-\tau)+\gamma \tau}\right)^{2}\left(\sigma_{N, f}^{2}+\sigma_{N, h}^{2}\right)
$$

\footnotetext{
${ }^{7}$ Because the capital stock is fixed at its deterministic steady state level we have that $y_{N}^{n}=\nu k_{s s}+\eta^{n}$, such that differences in per capita output of nontraded goods are equal to differences in the realization of productivity shocks.
} 
Second, more systemic countries - that is, countries that are either larger, more volatile, or both - tend to appreciate when the shadow price of traded goods is high. If country $f$ is more systemic than country $h$, we have

$$
\operatorname{cov}\left(s^{f, h}, \lambda_{T}\right)=\frac{\gamma(\gamma-1)(1-\tau)^{2}}{(1-\tau)+\gamma \tau}\left(\theta^{f} \sigma_{N, f}^{2}-\theta^{h} \sigma_{N, h}^{2}\right)>0
$$

The intuition for this result is as follows: whenever any country suffers a low productivity shock, the relative price of its nontraded goods rises and its real exchange rate appreciates. For a given percentage decline in productivity, this appreciation occurs independently of how large the country is (note that there is no $\theta$ in equation (21)). However, when a larger or more volatile country suffers this shock, more of it is transmitted to the rest of the world. For example, in states of the world in which the US (the largest economy in the world) draws a low productivity shock, it imports a lot of the world's traded goods, raising the shadow price of traded goods all over the world. As a result, the US dollar tends to appreciate when $\lambda_{T}$ is high, producing a positive covariance between the US real exchange rate and $\lambda_{T}$.

This heterogeneity in the stochastic properties of countries' exchange rates in turn generates heterogeneity in the incentive to invest across countries. In particular, it generates a larger incentive to invest in the capital stock of more systemic countries. Interpreting $k_{1}^{f}-k_{1}^{h}$ in 18 as the differential incentive to accumulate capital across two countries, we can show the following proposition:

\section{Proposition 1}

If markets are complete, and $\gamma>1$, more systemic countries have an incentive to accumulate more capital per worker:

$$
k_{1}^{f}-k_{1}^{h}=\frac{(\gamma-1)^{2}(\tau-1)^{2}}{2((\gamma-1) \tau+1)^{2}}\left(2(\gamma-1) \tau\left(\theta^{f} \sigma_{N, f}^{2}-\theta^{h} \sigma_{N, h}^{2}\right)+\left(\sigma_{N, f}^{2}-\sigma_{N, h}^{2}\right)\right)>0
$$

if country $f$ is more systemic than country $h$.

Proof. In each of the two periods, the marginal utility of consumption of households in 
country $n$ is

$$
\lambda^{n}=-\frac{\gamma \tau}{\phi} \bar{y}_{T}-\frac{\gamma \tau(1-\tau)(\gamma-\phi)}{\phi(\gamma \tau+(1-\tau) \phi)} \bar{y}_{N}-\frac{\gamma(1-\tau)}{\gamma \tau+(1-\tau) \phi} y_{N}^{n} .
$$

It follows immediately that the first term in $(18)$ is equal to zero because $\lambda_{0}^{n}=\mathbb{E} \lambda_{1}^{n}=0$. Differential incentives to accumulate capital thus only arise from the second term, that is, the difference in the volatility of marginal utilities of the two countries. These, in turn, result from differences in $\operatorname{cov}\left(\bar{y}_{N}, y_{N}^{n}\right)$ (the first term in the brackets in (22)) and from differences in the volatility of $y_{N}^{n}$ (the second term in the brackets).

It is efficient to accumulate more capital in more systemic countries because a larger capital stock in a more systemic country represents a good hedge against world-wide consumption risk. Households around the world worry about states of the world in which systemic countries suffer bad productivity shocks, because these shocks are transmitted to the rest of the world in the form of higher shadow prices of traded goods. Although households have no way of preventing these states from occurring, they can partially insure against them by accumulating more capital in more systemic countries. By doing so, they raise the unconditional mean level of output of nontraded goods in these countries across all states and thus soften the impact of adverse shocks.

Another way of thinking about this result is from the perspective of an international investor. Consider an investor who can buy units of capital all around the world. All else equal, she will prefer to invest in the capital stock of a more systemic country because systemic countries' currencies tends to appreciate in states of the world when the shadow price of traded goods, and thus the marginal utility of consumption around the world, is high. In this sense, systemic countries attract investment because they have "safe" currencies that appreciate in "bad" states of the world.

This simple, complete-markets model of exchange rate determination thus predicts a link between the stochastic properties of countries' real exchange rates and differential incentives to accumulate capital across countries. All else equal, larger countries and countries with more volatile exchange rates should have higher capital-output ratios in equilibrium. In the following subsection we argue that the logic of this result is quite general and does not rely on the specific assumption that financial markets are complete. 


\subsection{Monetary Shocks, Exchange Rates, and the Capital Stock}

While the complete-markets model is an important benchmark, it has a number of wellknown empirical shortcomings. First, it predicts a (perfect) negative correlation between appreciations of the real exchange rate and aggregate consumption growth - a country appreciates when its aggregate consumption falls. This follows directly from (16) and (21) (Backus and Smith, 1993). Second, real exchange rates seem much too volatile to be rationalized exclusively by real (productivity) shocks (Chari, Kehoe, and McGrattan, 2002). As a result, many authors have argued for incomplete market models that allow for an effect of monetary shocks on equilibrium real exchange rates.

In this subsection, we analyze the case in which markets are incomplete $(\phi<1)$. We will argue that allowing for market incompleteness can partially address both of the main empirical shortcomings of the complete-markets model outlined above, while preserving the main intuition that larger countries and countries with more volatile exchange rates should have higher capital-output ratios in equilibrium. To simplify the discussion, we first consider the case where productivity and endowments are deterministic $\left(\sigma_{N, n}, \sigma_{T, n}=0\right)$ before discussing the joint effects of real and monetary shocks.

Inactive households hold nominal bonds denominated in their national currencies and are thus vulnerable to inflation shocks. A positive inflation shock acts as an "inflation tax" on these households: the higher inflation, the less their nominal bonds are worth and the less they are able to consume (see equation (12)). However, since inflation shocks have no bearing on the real endowments available for consumption, this reduction of consumption on the part of inactive households must go to the benefit of active households in equilibrium.

Active households' equilibrium use of traded goods is

$$
i_{T}^{h}=\frac{1-\phi}{\phi} \mu^{h}+\frac{\gamma(\tau(1-\phi)+\phi)(1-\phi)}{(\gamma \tau+(1-\tau) \phi) \phi}\left(\bar{\mu}-\mu^{h}\right),
$$

where $\bar{\mu}=\sum_{n=1}^{N} \theta^{n} \mu^{n}$ is the weighted sum of inflation shocks in all countries. The first term on the right-hand side reflects the immediate rise in active households' consumption, which is proportional to the number of inactive households per active household. However, risk-sharing among active households residing in different countries requires that some of 
the initial rise in consumption be shared internationally, which is reflected in the second term on the right-hand side: whenever the domestic inflation shock exceeds the weighted average of inflation shocks around the world, $\bar{\mu}$, the home country ships traded goods to the rest of the world. This shipment of traded goods has two effects. First, it results in a fall in the relative price of nontraded goods in the domestic economy, such that the domestic currency depreciates in real terms whenever inflation is relatively high,

$$
s^{f, h}=\lambda^{f}-\lambda^{h}=-\frac{\gamma(\tau-1)(\phi-1)\left(\mu^{f}-\mu^{h}\right)}{\gamma \tau+(1-\tau) \phi} .
$$

Second, it lowers the shadow price of traded goods in the world:

$$
\lambda_{T}=-\frac{1-\phi}{\phi} \gamma \sum_{n=1}^{N} \theta^{n} \mu^{n}+\log (\tau)
$$

This expression is similar to (20) in that inflation shocks unambiguously lower $\lambda_{T}$, but only in proportion to the size of the country in which they originate. Inflation shocks in larger countries have a larger impact on the shadow price of traded goods than inflation shocks in smaller countries.

Inspecting (24) and (25) shows that, similar to the effect of productivity shocks, countries with more volatile inflation shocks tend to have more volatile exchange rates and that inflation shocks also result in a positive covariance between the exchange rates of more systemic countries and $\lambda_{T}$. The intuition for this result is also similar to the completemarkets case: whenever any country experiences a high inflation shock, active households receive more real resources, which lowers their marginal utility of consumption and leads to a depreciation of the real exchange rate. (The marginal utility of inactive agents is irrelevant for exchange rates because they do not access financial markets.) For a given inflation shock, this appreciation occurs independently of how large the country is. However, when a larger or more volatile country suffers this shock, more of it is transmitted to the rest of the world, as is apparent from (20). As a result, more systemic countries' exchange rates tend to depreciate when $\lambda_{T}$ is low, again producing a positive covariance between their real exchange rates and $\lambda_{T}$. 


\section{Proposition 2}

If financial markets are incomplete and the economy is affected only by inflation shocks, more systemic countries have an incentive to accumulate more capital per worker:

$$
k_{1}^{f}-k_{1}^{h}=\frac{\gamma^{2}(1-\phi)^{2}}{2(\gamma \tau+(1-\tau) \phi)^{2}}\left(\tilde{\sigma}_{f}^{2}-\tilde{\sigma}_{h}^{2}\right)+\frac{\gamma^{2}(1-\phi)^{2} \tau(\gamma-\phi)}{\phi(\gamma \tau+(1-\tau) \phi)}\left(\theta^{f} \tilde{\sigma}_{f}^{2}-\theta^{h} \tilde{\sigma}_{h}^{2}\right)>0
$$

if country $f$ is more systemic than country $h$.

Proof. See Appendix D.

The central insight from the complete-markets model thus holds even if markets are incomplete and variation in exchange rates is driven by monetary instead of real shocks. Appendix E shows that this is also true when the economy is simultaneously affected by both real and monetary shocks.

In addition to re-enforcing the main insight from the complete-markets case, allowing for market incompleteness also improves the fit of the model to the data in two critical dimensions (Alvarez et al., 2002; Kollmann, 2012). First, we demonstrate that the incomplete markets model with inflation shocks loosens or even reverses the negative correlation between appreciations of the real exchange rate and aggregate consumption growth. In a second step, we show that the incomplete markets model with inflation and productivity shocks may better fit the high volatility of real exchange rates observed in the data.

\section{Corollary 3}

If financial markets are incomplete and the economy is affected only by inflation shocks, real appreciations of the exchange rate are perfectly positively correlated with relative growth in aggregate consumption.

Proof. At the deterministic steady state, we have that log aggregate consumption is $\bar{c}^{n}=\phi c^{n}+(1-\phi)\left(-\mu^{n}\right)$. In each of the two periods, the marginal utility of consumption of active households in country $n$ is

$$
\lambda^{n}=-\frac{\gamma^{2} \tau(1-\phi)}{\phi(\gamma \tau+(1-\tau) \phi)} \bar{\mu}-\frac{\gamma((1-\phi)(1-\tau))}{\gamma \tau+(1-\tau) \phi} \mu^{n}
$$

Using the fact that $c^{n}=-\lambda^{n} / \gamma$ in conjunction with (24) and (26), we can write the 
covariance between the exchange rate and aggregate consumption as

$$
\operatorname{cov}\left(s^{f, h}, \bar{c}^{f}-\bar{c}^{h}\right)=\frac{\gamma^{2}(1-\tau) \tau(1-\phi)^{2}}{((1-\tau) \phi+\gamma \tau)^{2}}\left(\tilde{\sigma}_{f}^{2}+\tilde{\sigma}_{h}^{2}\right)>0
$$

and their correlation is one.

To see the intuition for this result again consider a country that experiences a positive inflation shock. Because active households within the country now have more real resources available, they ship traded goods to active households residing in other countries. As a result of this outflow of resources, aggregate consumption drops while their country's currency depreciates. Inflation shocks thus induce a positive association between aggregate consumption growth and appreciations.

By contrast, the productivity shocks discussed in the previous sub-section induce a negative association between aggregate consumption growth and appreciations: a country that experiences a negative productivity shock in the nontraded sector experiences a fall in aggregate consumption and a simultaneous appreciation. Because of these opposite signs in the association between aggregate consumption and appreciations, the full model with incomplete markets, real, and monetary shocks can produce any correlation between aggregate consumption and appreciations. For a range of parameters with $\phi<1$ it may thus resolve the Backus and Smith (1993) puzzle.

Similarly, allowing for market incompleteness may go some of the way in addressing the second main empirical shortcoming of the complete-markets model by increasing the volatility of the real exchange rate. The following expression shows the equilibrium real exchange rate when markets are incomplete $(\phi<1)$ and the economy is affected by productivity and inflation shocks $\left(\sigma_{N, n}, \tilde{\sigma}_{n}>0\right)$.

$$
s^{f, h}=\frac{\gamma(1-\tau)}{(1-\tau) \boldsymbol{\phi}+\gamma \tau}\left(y_{N}^{h}-y_{N}^{f}\right)+\frac{\gamma(1-\tau)(1-\phi)}{(1-\tau) \phi+\gamma \tau}\left(\mu^{h}-\mu^{f}\right)
$$

Comparing this expression with (21) shows two differences. First, and most obviously, the variance of the real exchange rate is now higher because inflation shocks represent an additional source of volatility. Second, market incompleteness increases the effect of a given productivity shock because fewer households engage in risk-sharing (the fraction in 
the first term is unambiguously larger than its counterpart in (21)).

We draw four main conclusions from the analysis of our simplified model. First, the stochastic properties of real exchange rates should predict differences in capital accumulation across countries: countries whose currencies appreciate when the shadow price of traded goods is high should accumulate more capital per capita. Second, absent a direct measure for the shadow price of traded goods, differences in country size and differences in the volatility of countries' real exchange rates serve as sufficient statistics for the relevant differences in the stochastic properties of real exchange rates. Third, these conclusions hold regardless of whether markets are complete or incomplete, and regardless of whether variation in exchange rates is driven by real or monetary shocks. Fourth, allowing for market incompleteness may help to address some of the empirical shortcomings of the complete-markets model.

\subsection{Link to the Asset Pricing Literature}

Before moving to the analysis of our quantitative model, it is useful to relate our main theoretical results to similar results in the asset pricing literature. The previous subsections derived Propositions 1 and 2 directly from condition (17), which pins down the optimal allocation of capital across countries without considering asset prices. Nevertheless, the results in the two propositions are closely linked to violations of uncovered interest parity and differences in the required rate of return on capital across countries. To see this link to the extant literature, consider pricing one unit of capital installed for the production

of nontraded goods in country $n$ that pays a stochastic return $\tilde{R}^{n}$ in terms of country $n$ 's final good. The consumption Euler equations of active households require that

$$
1=\beta \mathbb{E}\left(\frac{\Lambda_{1}^{n}}{\Lambda_{0}^{n}} \tilde{R}^{n}\right) .
$$

Taking logs of this expression, using the fact that the share of output accruing to capital is log-normally distributed, and differencing the resulting expression for units of capital installed in two different countries $h$ and $f$, we can write

$$
\mathbb{E} \tilde{r}_{1}^{f}+\mathbb{E} \Delta s^{f, h}-\mathbb{E} \tilde{r}_{1}^{h}=\frac{1}{2} \operatorname{var}\left(\lambda_{1}^{h}+\tilde{r}_{1}^{h}\right)-\frac{1}{2} \operatorname{var}\left(\lambda_{1}^{f}+\tilde{r}_{1}^{f}\right),
$$


where again lowercase variables stand for the natural log. Since the price of capital is known at time 0 , the only part of $\tilde{r}_{1}^{n}$ that has a variance is its payoff, which we can write as $\log \left(\frac{\Lambda_{N}^{n}}{\Lambda^{n}} \nu Y_{N}^{n}\right)=\log (\nu(1-\tau))-\frac{1}{\gamma} \lambda^{n}$. Applying this condition in the equation above reveals that the right hand side is then a function only of the difference in the variance of $\lambda^{h}$ and $\lambda^{f}$. Performing a similar calculation for a risk-free asset that pays one unit of country $n^{\prime}$ s final good with certainty at a risk-free rate of interest $r^{n}$, we can write

$$
\begin{aligned}
\mathbb{E} \tilde{r}_{1}^{f}+\mathbb{E} \Delta s^{f, h}-\mathbb{E} \tilde{r}_{1}^{h} & =\left(1-\frac{1}{\gamma}\right)^{2}\left(r^{f}+\mathbb{E} \Delta s^{f, h}-r^{h}\right) \\
& =\left(1-\frac{1}{\gamma}\right)^{2} \frac{1}{2}\left(\operatorname{var}\left(\lambda_{1}^{h}\right)-\operatorname{var}\left(\lambda_{1}^{f}\right)\right) \\
& =\left(k_{1}^{h}+\frac{\gamma-1}{\gamma} \mathbb{E} \Delta s^{f, h}-k_{1}^{f}\right),
\end{aligned}
$$

where the third equality uses (18). The difference in incentives to accumulate capital across countries is thus one of many manifestations of the effect of heterogeneity in the stochastic properties of countries' real exchange, which also include violations of uncovered interest parity and differences across countries in the required return to capital in the nontraded sector.

The prediction that larger and more volatile countries accumulate higher capitaloutput ratios is thus intimately linked to violations of uncovered interest parity, as defined in (Backus, Foresi, and Telmer, 2001), and consistent with a number of stylized facts about the objects in 290 that have been documented in the recent empirical literature. First, high interest rate currencies systematically depreciate when US consumption growth is low (Lustig and Verdelhan, 2007), a direct implication of applying (28) to a representative US household valuing the domestic returns to risk-free bonds denominated in foreign currencies. Second, a portfolio that is long high interest rate currencies and short low interest rate currencies is a priced factor in international currency markets Lustig et al., 2011), a direct implication of (28) and the second equality in (29). Third, larger countries' currencies have lower interest rates and pay lower expected returns (Hassan, 2013), a direct implication of combining Propositions 1 and 2 with (29). Fourth, the currencies of countries with more volatile nontraded sectors have lower interest rates and pay lower expected returns (Tran, 2013), and fifth, stocks in the nontraded but not the traded sector 
of larger countries pay lower expected returns and thus have a lower required return to capital (Hassan, 2013), both again direct implications of combining Propositions 1 and 2 with (29). In this sense, our model is also well-suited to qualitatively match a range of salient facts about cross-country variation in the returns on international assets.

Before concluding the discussion of the simplified version of the model it is worth noting that the link between capital accumulation, interest rates, and the required rate of return on capital becomes more complex when allowing for dynamics and an arbitrary elasticity of substitution between traded and nontraded goods. For example, one can show that the difference between two countries' risk-free interest rates and required rates of return on capital can invert for some range of parameters. Nevertheless this does not appear to be the case for the range of parameters that are empirically relevant, such that the intuition from our simplified model turns out to be useful for understanding the results of our quantitative exercise.

\section{Dynamic Model and Estimation}

Having derived the equilibrium relationship between the stochastic properties of countries' exchange rates and differences in capital-output ratios within our simplified model, we take the full model specified in section 2 to the data. We begin by calculating differences in capital-output ratios across countries that result only from heterogeneity in country size, while estimating the variance of productivity and inflation shocks to match the average variance of GDP growth and CPI inflation across countries. In a second step, we repeat the same procedure but allow for heteroskedastic productivity and inflation shocks across countries. We estimate the relative size of each country's shocks to match the variance of its equal-weighted average real and nominal exchange rates, subject to the constraint that we again match the average variance across countries of GDP growth and CPI inflation. In a third step, we modify the model to increase the absolute variation in capital-output ratios across countries. Note that the purpose of this series of estimations is not to explain exchange rates, but rather to show that capital-output ratios vary across countries in a way consistent with the cross-country differences in the stochastic properties of exchange rates observed in the data. 


\subsection{Data}

Our sample consists of annual data from all OECD member countries that had freely floating exchange rates from 1984 to 2010 according to the IMF. These are Australia, Canada, Japan, New Zealand, Switzerland, the United Kingdom, and the United States. We intentionally focus on this set of industrialized and relatively homogeneous countries with similar institutions, tax systems, and well-functioning markets to mitigate the concern that heterogeneity in these other factors may confound our analysis. We generate the change in log real and nominal exchange rates for each pair of these countries assuming free convertibility of currencies using annual nominal exchange rates against the US dollar and CPI deflators from the OECD database.

Following Hassan (2013), we interpret the size of country n's economy as its average share of GDP in the sample of seven countries,

$$
\theta^{n}=\sum_{t=1}^{T} \frac{1}{T} \frac{G D P_{t}^{n}}{\sum_{j=1}^{N} G D P_{t}^{j}} .
$$

We measure each country's capital-output ratio by dividing its capital stock at constant 2005 national prices (converted to US Dollars at purchasing power parity) from the Penn World Tables version 8.1 by real GDP from the same source and averaging across our sample period. We also calculate the average difference between each country's risk-free interest rate and the risk-free interest rate in the US using covered interest parity from data on forward and spot exchange rates following the procedure in Hassan and Mano (2014).

In addition, we use real GDP, CPI deflators, and population growth data from the OECD database to measure log per capita GDP growth and inflation growth for each country. Appendix F.1 gives additional details on our data sources and construction.

\subsection{Calibration and Estimation}

We begin by calibrating the parameters of our model to a set of standard values used in the literature, summarized in Table 1. We choose $\varepsilon_{\alpha}=0.44, \beta=0.99$, and $\delta=0.1$, consistent with Stockman and Tesar (1995). In addition, we choose standard values for relative risk 
aversion $(\gamma=10)$ and the capital share $(\nu=0.4)$. We set the expenditure share of traded goods in the production of final goods to $\tau=0.3$, reflecting that, in the data, a large proportion of the price of tradables accrues to nontradable retail services (Burstein, Neves, and Rebelo (2003) and Goldberg and Campa (2010)). The only parameter we have relatively little guidance on is the degree of market segmentation. For lack of a clear alternative, we set $\phi=0.26$, equal to the share of households in the United States who directly own stocks according to Giannetti and Koskinen (2010) ${ }^{8}$

Since the volatility of endowments of traded goods has no bearing on exchange rates or differential incentives to accumulate capital across countries, we choose $\sigma_{T}^{n}=0.1 \%$ for all countries. We consciously choose a small value for these shocks to maximize the ability of the model to match the volatility of equilibrium exchange rates, as will become apparent below.

We estimate the volatility of the remaining fourteen productivity shocks and inflation shocks using a Simulated Methods of Moments procedure. Our estimator is the parameter vector $\hat{\Phi}$ that minimizes the distance between a vector of empirical moments, $H_{D}$, and the corresponding moments generated by the model, $H(\hat{\Phi})$. This estimator $\hat{\Phi}$ is given by:

$$
\begin{aligned}
& \hat{\Phi}=\arg \min _{\Phi}\left[H(\Phi)-H_{D}\right]^{\prime}\left[H(\Phi)-H_{D}\right] \\
& \text { s.t. } \sigma_{N, n}>0 \text { and } \tilde{\sigma}_{n}>0 .
\end{aligned}
$$

For a given parameter vector, $\Phi$, we create 1,000 synthetic time series, each of length equal to our sample size. On each sample, we calculate the sample moments of interest. The vector $H(\Phi)$ that enters the loss function is the average value of the sample moments across the synthetic time series. Consistent with our data, we assume agents make decisions at the annual frequency and derive the model's implications for data moments computed at the annual frequency:9

\footnotetext{
${ }^{8}$ We also consider an alternative specification in which we chose $\phi$ to match the share of the US population that directly holds foreign stocks in their financial portfolio (Nechio, 2010).

${ }^{9}$ Given that capital-output ratios are slow moving objects and the recent evidence by Rabanal and Rubio-Ramirez (2015) it is likely that we would get a better fit when matching the stochastic properties of exchange rates measured at lower frequencies. Nevertheless we choose the annual frequency for comparability to the majority of the existing literature.
} 
In our baseline specification, the target vector $H_{D}$ contains a total of 16 empirical moments. The first seven moments are the variances of each country's equally-weighted average real exchange rate with all other countries in the sample normalized by the average of these variances across countries,

$$
\frac{\operatorname{var}_{n}\left(\sum_{j \neq n} \frac{1}{N-1} \Delta s_{t}^{n, j}\right)}{\sum_{n} \frac{1}{N} \operatorname{var}_{n}\left(\sum_{j \neq n} \frac{1}{N-1} \Delta s_{t}^{n, j}\right)} .
$$

The rationale for focusing on equally weighted average exchange rates rather than tradeweighted average exchange rates is to isolate the variance of real and monetary shocks specific to each country while averaging out the shocks affecting all other countries as in Verdelhan (2014) 10 The following seven moments are the nominal counterparts of these moments: the variances of each country's equally-weighted average nominal exchange rate with all other countries in the sample, again normalized by the average of these variances across countries. The purpose of normalizing with averages is to avoid rewarding the estimator for choosing implausibly volatile real and monetary shocks to match the (high) average volatility of exchange rates in the data. (This is the well-known exchange rate volatility puzzle.) Instead, we anchor the average level of real and monetary shocks by including the average variance of GDP growth across countries and the average variance of CPI inflation across countries in the target vector.

Beyond these details, the crucial feature of the target vector is that it only contains information about the variability of exchange rates, output, and inflation, and no information about capital accumulation, interest rates, or any variable directly related to it. The number of parameters to be estimated depends on our assumptions about the covariance matrix for the shocks, and varies across different specifications.

\footnotetext{
${ }^{10}$ Using equal-weighted averages is not essential for our results. Nevertheless note from (27) we have that $\lim _{N \rightarrow \infty} \sum_{j \neq n} \frac{1}{N-1} s_{t}^{n, j}=-\frac{\gamma(1-\tau)}{(1-\tau) \phi+\gamma \tau} y_{N}^{f}-\frac{\gamma(1-\tau)(1-\phi)}{(1-\tau) \phi+\gamma \tau} \mu^{f}$, such that in a large sample of countries, the equally weighted average exchange rate isolates country-specific shocks, making this measure appealing on theoretical grounds.
} 


\subsection{Results}

In our first empirical exercise, we constrain the variance of productivity and inflation shocks to be constant across countries $\left(\sigma_{N, n}=\sigma_{N}\right.$ and $\left.\tilde{\sigma}_{n}=\tilde{\sigma}\right)$. Column 2 of Table 2 and column 1 of Figure 1 show the results of this "homoskedastic" calibration. The estimated standard deviation of productivity and inflation shocks are $\sigma_{N, n}=1.96 \%$ and $\tilde{\sigma}=0.01 \%$, respectively. Given these parameters, the model roughly matches the average standard deviation of output and inflation across countries $(2.01 \%$ and $2.15 \%$ in the model versus $1.99 \%$ and $1.87 \%$ in the data, respectively) but produces a counterfactually large negative correlation between aggregate consumption growth and appreciations of the real exchange rate $(-0.887$ versus -0.012 in the data) .

Because shocks are homoskedastic across countries, differences in country size are the only source of variation in the stochastic properties of countries' exchange rates and thus the only potential driver of differences in capital-output ratios in this calibration. Panel A of Figure 1 shows a slightly positive association between the model-implied and empirical capital-output ratios. In this sense, heterogeneity in country size accounts for $7 \%$ of the variation in relative capital-output ratios across the seven countries in our sample. Similarly, Panel B shows an only slightly positive association between model-implied and empirical mean risk-free interest rates across countries.

Panel C plots the model-implied and empirical variances of each country's equallyweighted average real exchange rates. It shows a horizontal line, reflecting the fact that differences in country size have no effect on the variance of exchange rates. The same is true for the variances of nominal exchange rates (not shown).

To motivate our next calibration, we regress differences in capital-output ratios on a constant term and our measure of country size. We then plot the residuals of this regression over the average variance of each country's bilateral exchange rates in Figure 2. The plot shows a positive association between the two variables consistent with the predictions of Propositions 1 and 2: Countries with more volatile exchange rates tend to have higher capital-output ratios, accounting for more than half of the residual variation that is not accounted for by differences in country size. This piece of evidence is modelfree. We now ask whether the version of our model with heteroskedastic productivity and 
inflation shocks is consistent with observed patterns of capital-output ratios.

In our second, "heteroskedastic" calibration, we explore this possibility by examining how differences in the volatility of productivity and inflation shocks can improve the model's predictions. We repeat our estimation procedure, but now allow heteroskedastic productivity and inflation shocks across countries, such that the vector $\Phi$ now contains the pair $\left(\sigma_{N, n}, \tilde{\sigma}_{n}\right)$ for all $n$. The results of this estimation are in Column 3 of Table 2 and column 2 of Figure 1 .

Column 3 of Table 2 shows that this heteroskedastic calibration again fits almost perfectly the cross-country averages of the standard deviation of GDP growth and inflation but now gives a better fit for the average correlation of aggregate consumption growth and appreciations in the data (-0.21 versus -0.01$)$.

More importantly, Panel A of Figure 1 shows that allowing for heteroskedastic shocks, and thus heterogeneity in the volatility of exchange rates across countries, significantly increases the correlation between empirical and model-implied capital-output ratios. The regression line shown in the plot accounts for $72 \%$ of the variation in the data. In this sense, the stochastic properties of exchange rates, as proxied by differences in country size and the variances of exchange rates, can account for the majority of the differences in relative capital-output ratios across the countries in our sample. Panel B shows that the same is true for cross-country variation in mean risk-free rates $\left(R^{2}=0.57\right)$, where countries with more volatile exchange rates also tend to have lower risk-free interest rates, as predicted by the model ${ }^{11}$ By design, the estimation now almost fully achieves its targets by matching the relative differences in the volatility of real and nominal exchange rates across countries. (Panel $\mathrm{C}$ shows an $R^{2}$ of 0.99 for the relative variances of real exchange rates. The corresponding $R^{2}$ for the nominal moments is also 0.99, not shown.)

Although the model does remarkably well in predicting the relative differences in capital-output ratios across countries, it fails significantly on magnitudes. The slope of the regression line in Panel A is orders of magnitude smaller than one (0.001), reflecting the fact that the absolute size of the model-predicted differences is small compared to

\footnotetext{
${ }^{11}$ This figure shows nominal interest rate differentials measured by each country's forward premia against the United States. Figure 3 shows the corresponding figure if we use real interest rates. The two figures are very similar. We calculate real interest rates by correcting the forward premia data with realized inflation. Details are given in Appendix F.2.
} 
those in the data. For example, in the data, Canada has a 30\% lower capital-output ratio than the United States. The model predicts a difference of around 0.03\%. Similarly, the slope coefficients in Panels B and C are 0.002 and 0.16, respectively, revealing that the model also under-predicts the absolute size of differences in risk-free interest rates and the average variance of real exchange rates by more than an order of magnitude. We conjecture that the model's failure to match the quantitative magnitude of the differences in capital-output ratios may be related to the well-known failure of the canonical model to generate (i) sufficiently large risk premia (and thus sufficiently large variation in risk-free interest rates across countries) and (ii) sufficient variability of the real exchange rate.

In Table 3, we attempt to address the latter issue by applying two modifications to the model that increase the variance of the real exchange rate. To this end we remove the average variances of GDP growth and inflation from the target vector and instead target the average variance of real and nominal exchange rates. In column 1 we add capital adjustment costs to our model of the form suggested by Jermann (1998), such that the equation of motion of the capital stock is now

$$
K_{t+1}=(1-\delta) K_{t}+I_{t}-G_{t} K_{t}
$$

where

$$
G_{t}=\frac{I_{K, t}}{K_{t}}-\left(\frac{v_{1}}{1-\frac{1}{\xi}}\left(\frac{I_{K, t}}{K_{t}}\right)^{1-\frac{1}{\xi}}+v_{0}\right)
$$

and $v_{0}$ and $v_{1}$ are constants calibrated such that $G_{t}=0$ and $\partial G_{t} / \partial\left(I_{t} / K_{t}\right)=0$ at the deterministic steady state. Under this specification it is costly to adjust the capital stock quickly, such that shocks are harder to absorb by increasing and decreasing the level of capital installed, increasing the effect of a given shock on marginal utility. To maximize the effect of this modification to the model we set $\xi=2$, which is the highest level of adjustment costs suggested by Jermann (1998).

The table shows that the model is now able to match the variance of real and nominal exchange rates almost perfectly (the slopes of regression lines relating model-implied and empirical variances of real and nominal exchange rates are now 0.94 and 0.96, respectively), albeit at the cost of significantly exceeding the variance of inflation $(6.76 \%$ versus 
$1.98 \%$ in the data). With this modification, the absolute differences in capital-output ratios increase by a factor of five such that the slope corresponding to Panel A in Figure 1 is now 0.005 rather than 0.001 .

In column 2 we go one step further and increase market segmentation to $\phi=0.04$, such that it is approximately equal to the share of the US population that directly holds foreign stocks in their financial portfolio (Nechio, 2010). The results of this calibration are similar but now produce a slope corresponding to Panel A in Figure 1 of 0.01. Both modifications thus go part of the way in terms of generating more volatile real exchange rates (ii) but nevertheless fail to generate sufficiently large differences in capital-output ratios.

We believe that this latter failure persists because the model is unable to generate sufficiently large risk and equity premia (i) even when it generates volatile exchange rates. An interesting avenue for future research would be to augment the model with remedies developed in the literature on the equity premium puzzle, such as long-run risk, rare events, or habit formation. In closed economy models, these remedies effectively increase the variance of investors' marginal utility. It is thus plausible that they could also increase the absolute differences in variances of marginal utility across countries when applied to a setting similar to ours. However, implementing such remedies in a multilateral model of exchange rate determination with asymmetric countries poses considerable technical difficulties that are beyond the scope of this paper.

One caveat to our interpretation remains. Our model purely focuses on capital accumulation in the nontraded sector. One could imagine a more complex model in which capital accumulation also takes place in the traded sector. This modification would change the results only if productivity in the traded sector was more variable in more systemic countries. However, the findings are likely to be robust to this extension for the following reasons. First, the nontraded sector makes up a relatively large part of the economy. Second, inflation shocks seem quantitatively important and have effects only on capital accumulation in the nontraded but not the traded sector. And third, there is almost no relation between the variance of GDP growth and the variance of exchange rates in the data. Therefore, the variance of productivity in the traded sector is likely to be smaller for more systemic countries which suggests higher capital accumulation in the traded sector. 


\section{Conclusion}

A growing literature in asset pricing centers on the idea that "safe haven" currencies appreciate in "bad" times, linking heterogeneity in the stochastic properties of exchange rates to violations of uncovered interest parity, differences in currency risk premia, and differences in equity returns across countries. In this paper, we have argued that, beyond affecting asset prices, this heterogeneity should have real effects: Countries whose currencies appreciate when the shadow price of traded goods is high should have lower cost of capital for the production of nontraded goods and, as a consequence, accumulate higher capital-output ratios for the production of these goods. In a simple quantitative application of our model, we find strong support for this prediction: Differences in stochastic properties of real exchange rates can account for $72 \%$ of the variation in relative capital-output ratios across seven industrialized countries.

The tentative conclusion of our analysis is that variation in exchange rates may not be as disconnected from economic fundamentals as previously thought. Stochastic properties of countries' exchange rates appear to line up with variation in capital-output ratios across countries in the way predicted by our model. Nevertheless, we interpret our results with due caution. First, our estimation is based on a sample of relatively homogeneous developed countries that have similar institutions, tax systems, and well-functioning markets. This relative homogeneity may explain why we get a good fit to the data even without controlling for these other factors. Second, our model matches only relative differences but falls far from the mark in matching the magnitude of absolute differences. We conjecture that this failure to match magnitudes is connected to the model's failure to generate sufficient volatility in the real exchange rate and to match the magnitude of the equity premium, both of which are well-established issues in the literature. We believe a crucial next step may be to combine our framework with some of the remedies that have been developed for these issues, such as long-run risk, rare events, or habit formation, along the lines of recent work by Colacito, Croce, Ho, and Howard (2012) and Colacito, Croce, Gavazzoni, and Ready (2014) ${ }^{12}$

Beyond more quantitative applications, a link between the stochastic properties of

\footnotetext{
${ }^{12}$ See Colacito and Croce (2011), Verdelhan (2010), Heyerdahl-Larsen (2014), and Stathopoulos (2012) for other promising approaches that apply habit-formation or long-run risk in open-economy models.
} 
exchange rates and factor allocation across countries also poses interesting normative questions because it may create incentives to manipulate these stochastic properties. In Hassan, Mertens, and Zhang (2015), we take a step in this direction by studying the effect of currency pegs on capital accumulation across countries.

\section{References}

Alvarez, F., A. Atkeson, and P. J. Kehoe (2002). Money, interest rates, and exchange rates with endogenously segmented markets. Journal of Political Economy 110(1), 73-112.

Backus, D. K., S. Foresi, and C. I. Telmer (2001). Affine term structure models and the forward premium anomaly. The Journal of Finance 56(1), 279-304.

Backus, D. K. and G. W. Smith (1993). Consumption and real exchange rates in dynamic economies with non-traded goods. Journal of International Economics 35, 297-316.

Baxter, M., U. J. Jermann, and R. G. King (1998). Nontraded goods, nontraded factors and international non-diversification. Journal of International Economics 44, 211-229.

Bergin, P. R. and G. Corsetti (2015). International competitiveness and monetary policy. Unpublished Manuscript.

Burstein, A. T., J. C. Neves, and S. Rebelo (2003). Distribution costs and real exchange rate dynamics during exchange-rate-based stabilizations. Journal of Monetary Economics 50(6), $1189-1214$.

Campbell, J. Y., K. Serfaty-De Medeiros, and L. M. Viceira (2010). Global currency hedging. The Journal of Finance 65(1), 87-121.

Chari, V. V., P. J. Kehoe, and E. R. McGrattan (2002). Can sticky price models generate volatile and persistent real exchange rates? The Review of Economic Studies 69(3), $533-563$.

Coeurdacier, N. (2009). Do trade costs in goods market lead to home bias in equities? Journal of International Economics 7r(1), 86-100. 
Colacito, R., M. Croce, F. Gavazzoni, and R. Ready (2014). Currency risk factors in a recursive multi-country economy. mimeo University of North Carolina.

Colacito, R., M. Croce, S. Ho, and P. Howard (2012). Bkk the ez way. mimeo University of North Carolina.

Colacito, R. and M. M. Croce (2011). Risks for the long run and the real exchange rate. Journal of Political Economy 119(1), 153 - 181.

Collard, F., H. Dellas, B. Diba, and A. Stockman (2007, October). Goods trade and international equity portfolios. NBER Working Paper No. 13612.

David, J. M., E. Henriksen, and I. Simonovska (2014). The risky capital of emerging markets. Technical report, National Bureau of Economic Research.

Devereux, M. B., G. W. Smith, and J. Yetman (2009, March). Consumption and real exchange rates in professional forecasts. Working Paper 14795, National Bureau of Economic Research.

Engel, C. (2014). Chapter 8 - exchange rates and interest parity. In K. R. Elhanan Helpman and G. Gopinath (Eds.), Handbook of International Economics, Volume 4 of Handbook of International Economics, pp. 453 - 522. Elsevier.

Epstein, L. G. and S. E. Zin (1989). Substitution, risk aversion, and the temporal behavior of consumption and asset returns: A theoretical framework. Econometrica: Journal of the Econometric Society, 937-969.

Fornaro, L. (2015). Financial crises and exchange rate policy. Journal of International Economics.

Giannetti, M. and Y. Koskinen (2010, February). Investor Protection, Equity Returns, and Financial Globalization. Journal of Financial and Quantitative Analysis 45(01), $135-168$.

Goldberg, L. S. and J. M. Campa (2010). The sensitivity of the cpi to exchange rates: Distribution margins, imported inputs, and trade exposure. The Review of Economics and Statistics 92(2), 392-407. 
Govillot, N., H. Rey, and P. Gourinchas (2010). Us external returns and the exorbitant duty. 2010 Meeting Papers 371, Society for Economic Dynamics.

Hall, R. E. and C. Jones (1997). Levels of economic activity across countries. American Economic Review 87(2), 173-77.

Hassan, T. A. (2013). Country size, currency unions, and international asset returns. The Journal of Finance 68(6), 2269-2308.

Hassan, T. A. and R. Mano (2015). Forward and spot exchange rates in a multi-currency world. mimeo University of Chicago.

Hassan, T. A. and R. C. Mano (2014). Forward and spot exchange rates in a multicurrency world. Technical report, National Bureau of Economic Research.

Hassan, T. A., T. M. Mertens, and T. Zhang (2015). Currency manipluation. mimeo University of Chicago.

Heyerdahl-Larsen, C. (2014). Asset Prices and Real Exchange Rates with Deep Habits. Review of Financial Studies 27(11), 32800-3317.

Hsieh, C.-T. and P. J. Klenow (2009). Misallocation and manufacturing tfp in china and india. The Quarterly journal of economics 124(4), 1403-1448.

Jermann, U. J. (1998, April). Asset pricing in production economies. Journal of Monetary Economics $41(2), 257-275$.

Jorgenson, D. (1996). Investment - Vol. 2: Tax Policy and the Cost of Capital. MIT Press.

Karabarbounis, L. and B. Neiman (2014). The global decline of the labor share. Quarterly Journal of Economics 129(1), 61-103.

Kollmann, R. (2002). Monetary policy rules in the open economy: effects on welfare and business cycles. Journal of Monetary Economics.

Kollmann, R. (2012). Limited asset market participation and the consumption-real exchange rate anomaly. Canadian Journal of Economics. 
Lewis, K. K. (2011). Global asset pricing. Annual Review of Financial Economics 3(17261), $435-466$.

Lustig, H., N. Roussanov, and A. Verdelhan (2011). Common risk factors in currency markets. Review of Financial Studies 24(11), 3731-3777.

Lustig, H. and A. Verdelhan (2007). The cross section of foreign currency risk premia and consumption growth risk. American Economic Review 97(1), 89-117.

Maggiori, M. (2013). Financial intermediation, international risk sharing, and reserve currencies. Mimeo.

Martin, I. (2012). The forward premium puzzle in a two-country world. Mimeo.

Menkhoff, L., L. Sarno, M. Schmeling, and A. Schrimpf (2012). Carry trades and global foreign exchange volatility. Journal of Finance 67(2), 681-718.

Nechio, F. (2010). Foreign stock holdings: the role of information. Working Paper Series 2010-26, Federal Reserve Bank of San Francisco.

Rabanal, P. and J. F. Rubio-Ramirez (2015). Can international macroeconomic models explain low-frequency movements of real exchange rates? Journal of International Economics 96(1), 199-211.

Ready, R., N. Roussanov, and C. Ward (2013). Commodity trade and the carry trade: a tale of two countries. NBER Working Papers 19371, National Bureau of Economic Research, Inc.

Richmond, R. (2015). Trade network centrality and the currency carry trade. Mimeo $U C L A$.

Stathopoulos, A. (2012). Portfolio Home Bias and External Habit Formation. 2012 Meeting Papers 502, Society for Economic Dynamics.

Stockman, A. C. and H. Dellas (1989). International portfolio nondiversification and exchange rate variability. Journal of International Economics 26, 271-289. 
Stockman, A. C. and L. L. Tesar (1995). Tastes and technology in a two-country model of the business cycle: Explaining international comovements. American Economic Review $85,168-185$.

Tesar, L. L. (1993). International risk-sharing and non-traded goods. Journal of International Economics 35, 69-89.

Tran, N.-K. (2013). Growth risk of nontraded industries and asset pricing. Mimeo Olin Business School.

Verdelhan, A. (2010). A habit-based explanation of the exchange rate risk premium. Journal of Finance 65(1), 123-146.

Verdelhan, A. (2014). The share of systematic risk in bilateral exchange rates. mimeo MIT Sloan. 
Table 1: Calibrated Parameters

\begin{tabular}{ccc}
\hline \hline Parameter & Value & \multicolumn{2}{c}{ Reference } \\
\hline$\epsilon_{\alpha}=1 /(1-\alpha)$ & 0.44 & Stockman and Tesar \\
$\beta$ & 0.99 & Stockman and Tesar \\
$\delta$ & 0.10 & Stockman and Tesar \\
$\gamma$ & 10.00 & \\
$\nu$ & 0.40 & \\
$\tau$ & 0.30 & Burstein, Neves, and Rebelo (2003) \\
$\phi$ & 0.26 & Giannetti and Koskinen (2010) \\
$\sigma_{T}(\%)$ & 0.10 & \\
\hline \hline
\end{tabular}

Notes: Parameters used in our homoskedastic and heteroskedastic calibrations. All calibrations are to annual data for seven industrialized economies. $\varepsilon_{\alpha}$ denotes the elasticity of substitution between traded and nontraded goods, $\beta$ the time discount factor, $\delta$ the depreciation rate of capital, $\gamma$ the coefficient of relative risk aversion, $\nu$ the capital share of output, $\tau$ the expenditure share of traded goods, $\phi$ the share of each country's population that has access to complete international asset markets, and $\sigma_{T}$ the standard deviation of the log endowment of traded goods. 
Table 2: Estimation Results

\begin{tabular}{|c|c|c|c|c|}
\hline & & (1) & (2) & (3) \\
\hline & & Data & Homoskedastic & Heteroskedastic \\
\hline & & & Calibration & Calibration \\
\hline \multicolumn{2}{|l|}{ Panel A } & \multicolumn{3}{|c|}{ Estimated Parameters } \\
\hline \multirow[t]{7}{*}{ Productivity Shocks } & $\sigma_{N}^{A U S}(\%)$ & & 1.96 & 1.99 \\
\hline & $\sigma_{N}^{C A N}(\%)$ & & 1.96 & 1.52 \\
\hline & $\sigma_{N}^{C H E}(\%)$ & & 1.96 & 2.22 \\
\hline & $\sigma_{N}^{G B R}(\%)$ & & 1.96 & 1.69 \\
\hline & $\sigma_{N}^{J P N}(\%)$ & & 1.96 & 2.91 \\
\hline & $\sigma_{N}^{N Z D}(\%)$ & & 1.96 & 1.21 \\
\hline & $\sigma_{N}^{U S A}(\%)$ & & 1.96 & 1.84 \\
\hline \multirow[t]{7}{*}{ Inflation Shocks } & $\tilde{\sigma}^{A U S}(\%)$ & & 0.01 & 0.11 \\
\hline & $\tilde{\sigma}^{C A N}(\%)$ & & 0.01 & 0.01 \\
\hline & $\tilde{\sigma}^{C H E}(\%)$ & & 0.01 & 0.27 \\
\hline & $\tilde{\sigma}^{G B R}(\%)$ & & 0.01 & 0.05 \\
\hline & $\tilde{\sigma}^{J P N}(\%)$ & & 0.01 & 0.32 \\
\hline & $\tilde{\sigma}^{N Z D}(\%)$ & & 0.01 & 0.01 \\
\hline & $\tilde{\sigma}^{U S A}(\%)$ & & 0.01 & 0.16 \\
\hline \multicolumn{2}{|l|}{ Panel B } & \multicolumn{3}{|c|}{ Additional Targeted Moments } \\
\hline \multicolumn{2}{|c|}{ Avg. std(GDP growth) } & 1.99 & 2.01 & 1.99 \\
\hline & & $(0.13)$ & & \\
\hline \multirow{2}{*}{\multicolumn{2}{|c|}{ Avg. std(inflation) }} & 1.87 & 2.15 & 2.18 \\
\hline & & $(0.09)$ & & \\
\hline \multicolumn{2}{|l|}{ Panel C } & \multicolumn{3}{|c|}{ Non-targeted Moments } \\
\hline \multicolumn{2}{|c|}{ Avg. Corr(agg. cons. growth, rer) } & -0.012 & -0.94 & -0.21 \\
\hline
\end{tabular}

Notes: The table shows estimated parameters (Panel A) and moments generated (Panels $\mathrm{B}$ and $\mathrm{C}$ ) by our homoskedastic and heteroskedastic calibrations. 'Avg. std(x)' stands for the average standard deviation of $\mathrm{x}$ across countries. We present the standard deviation of the average standard devation of $\mathrm{x}$ in brackets. Standard errors on the empirical moments are bootstrapped (see Appendix F.2 for details). 'Avg. Corr(agg. cons. growth, rer)' stands for the average across countries of the correlation of aggregate consumption growth with real appreciations. Moments listed in columns 2 and 3 of Panels B and $\mathrm{C}$ are from simulated annual data for 4,0 00 years in 500 economies using Dynare++. We calculate the moments on each simulated economy and then average the simulated moments across economies. Column 1 shows the corresponding moments in the data. 


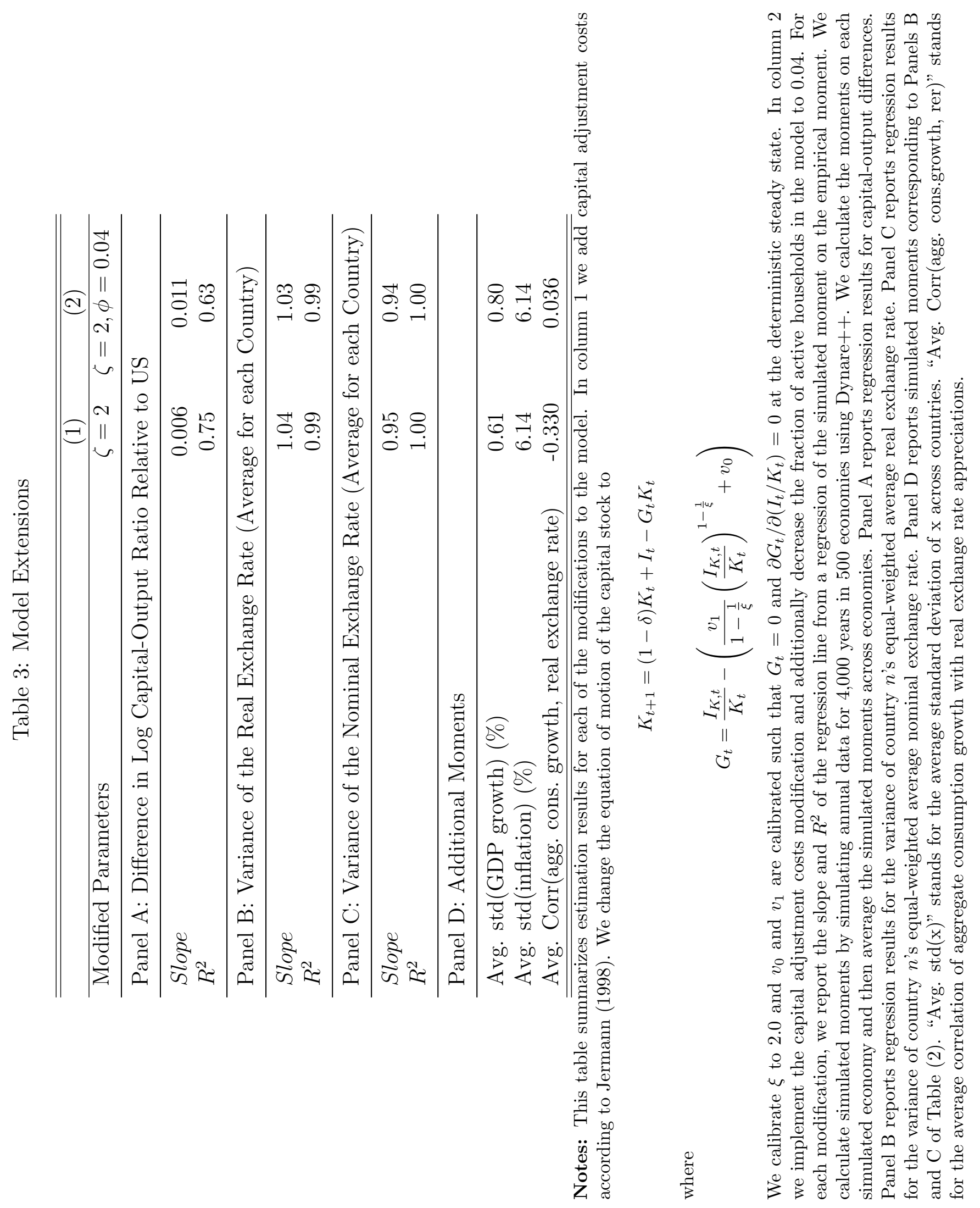


Notes: Figure 1 plots the results of our empirical exercise. We calculate and plot simulated moments against their empirical counterparts. We calculate simulated moments by simulating annual data for 4,000 years in 500 economies using Dynare++. We calculate the moments on each simulated economy and the average the simulated moments across economies. Column (1) presents results for the homoskedastic calibration and column (2) presents results for the heteroskedastic calibration. The slope and $R^{2}$ of the regression lines are listed below each figure. Panel A plots differences in log capital-output ratios. In our model, the capital-output ratio in period $t$ in country $n$ is $\ln \left(K_{t}^{n} / Y_{t}^{n}\right)=(1-\nu) \ln \left(K_{t}^{n} / \theta^{n}\right)$. Panel B plots the interest rate differential relative to the United States dollar. Panel $\mathrm{C}$ plots the variance of each country's equal-weighted average real exchange rate. 
Figure 1: Estimation Results
(1) Homoskedastic Calibration
(2) Heteroskedastic Calibration

Panel A: Mean Difference in Log Capital-Output Ratio Relative to US
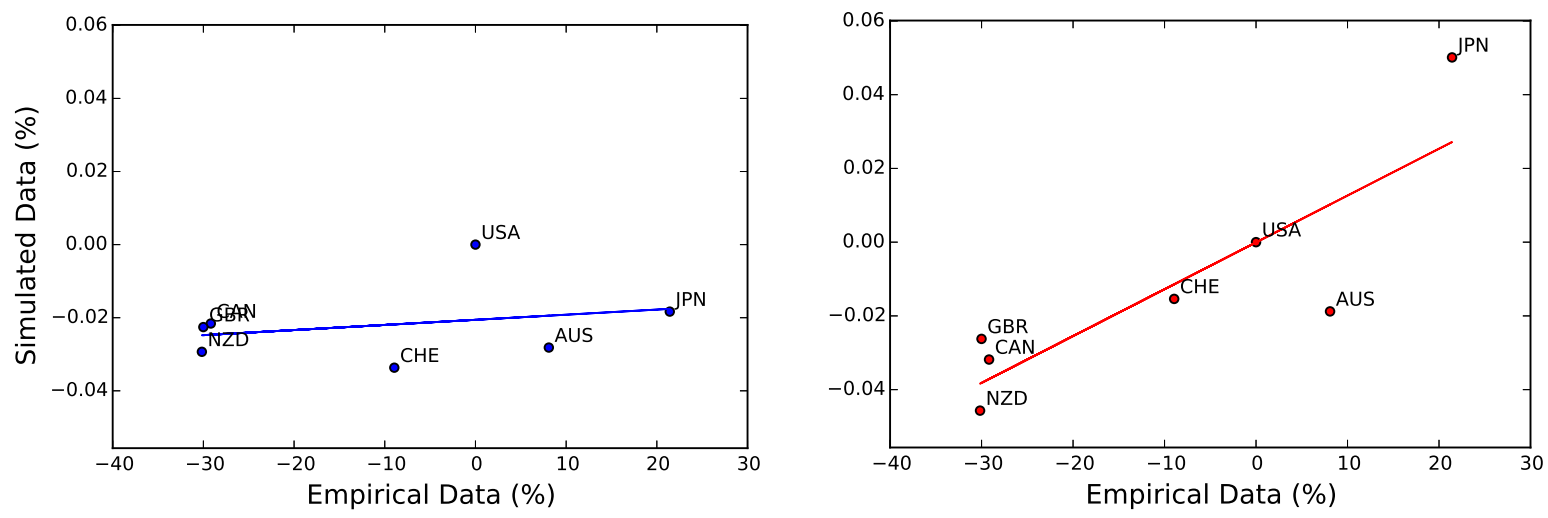

Slope $=0.000, R^{2}=0.07$

Slope $=0.001, R^{2}=0.72$

Panel B: Mean Interest Rate Differential Relative to US Dollar
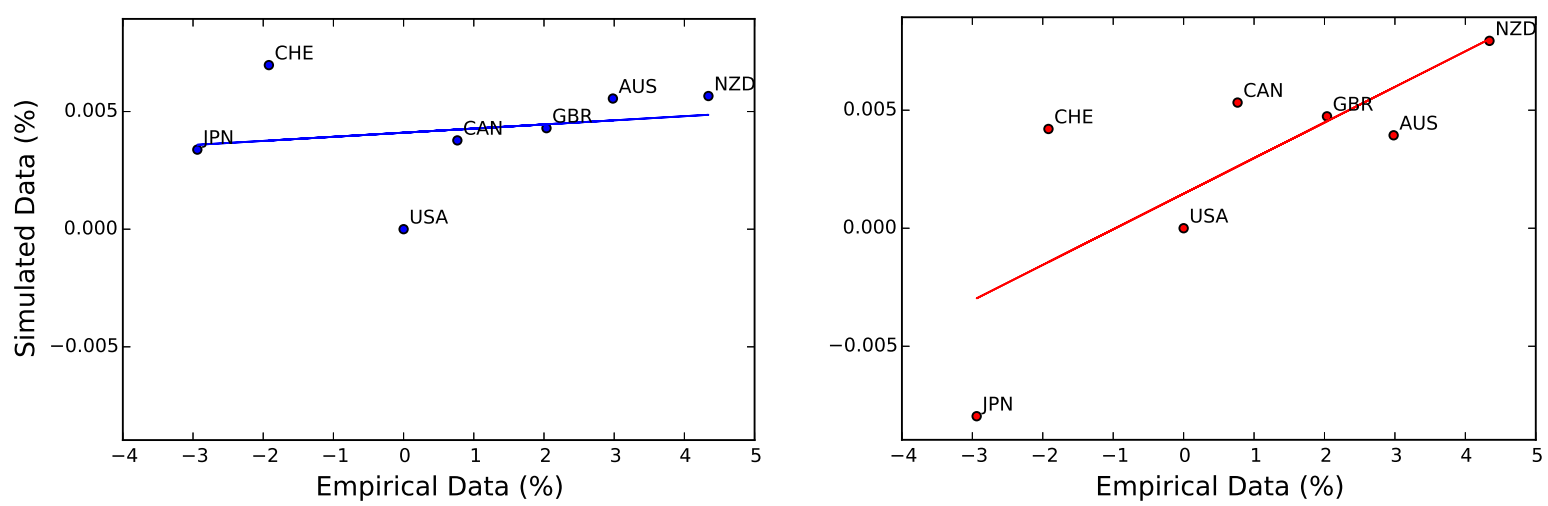

Slope $=0.0002, R^{2}=0.04$

Slope $=0.002, R^{2}=0.57$

Panel C: Variance of the Average Real Exchange Rate

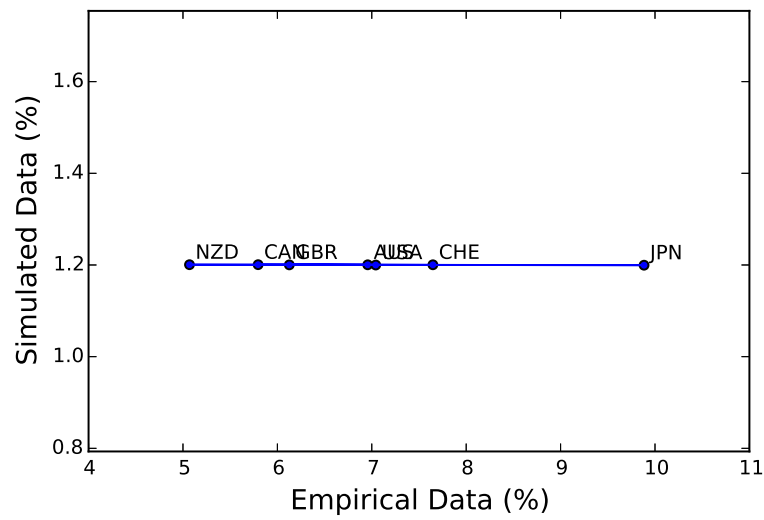

Slope $=-0.000, R^{2}=0.62$

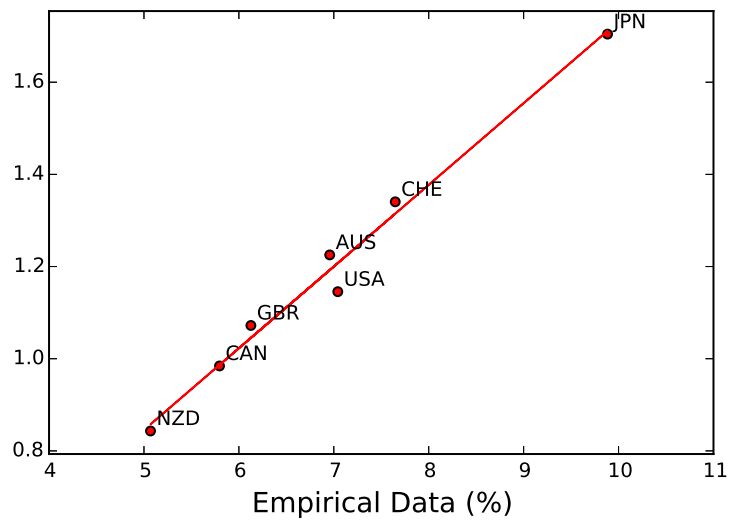

Slope $=0.16, R^{2}=0.99$ 
Figure 2: Reduced-form Results

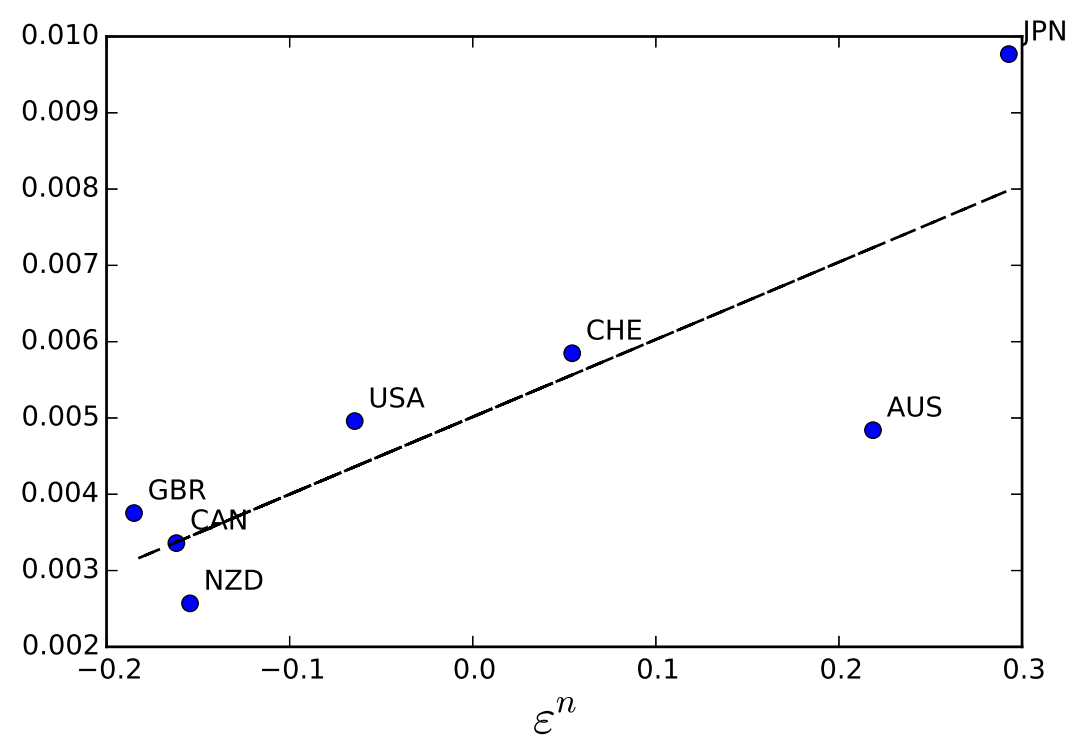

Notes: The figure plots residuals from a regression of differences in capital-output ratios on a constant term and our measure of country size over the variance of each country's average exchange rate. Residuals are generated using the specification

$$
\log \left(K^{n} / Y^{n}\right)-\log \left(K^{U S A} / Y^{U S A}\right)=\alpha_{n}+\beta_{n} \theta^{n}+\varepsilon^{n} .
$$

We calculate the variance of country $n$ 's average real exchange rate in period $t$ according to

$$
\operatorname{var}_{n}\left(\sum_{j \neq n} \frac{1}{N-1} \Delta s_{t}^{n, j}\right)
$$

The regression line has a slope of 0.01 and an $R^{2}$ of 0.69 . 
Figure 3: Real Interest Rate Differential Corrected for Realized Inflation

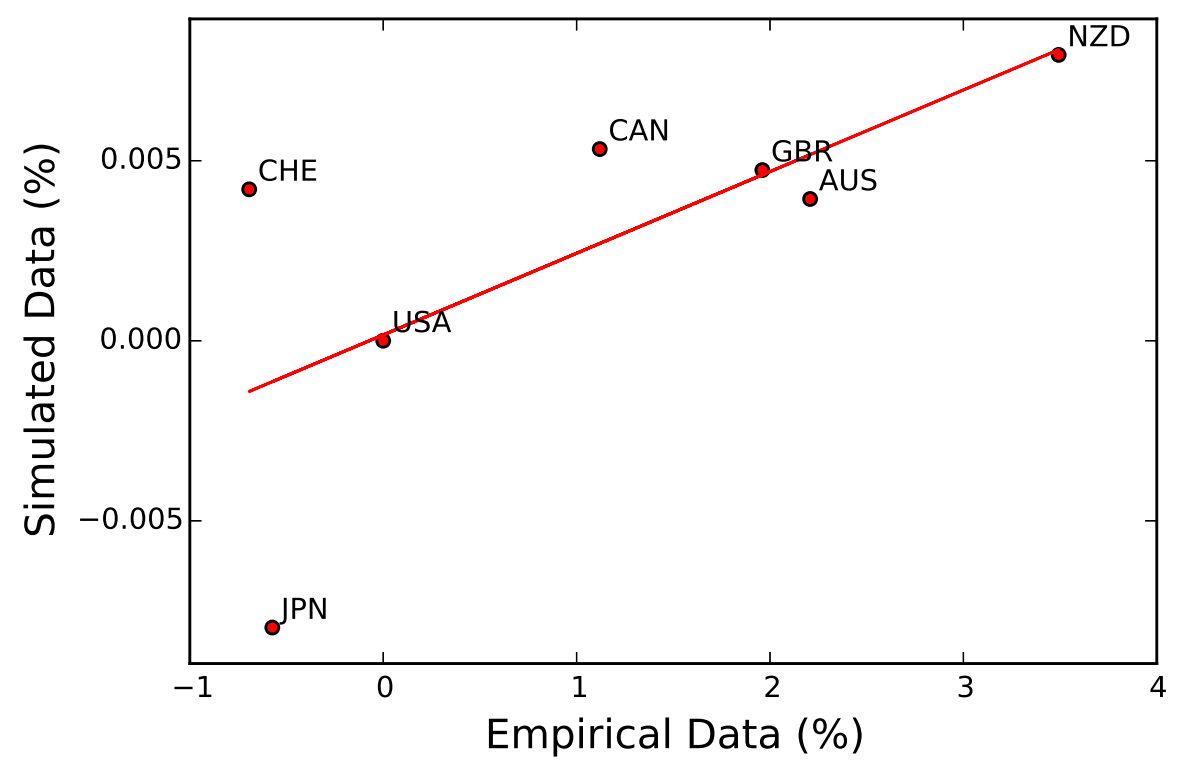

Notes: This figure plots real interest rate spreads generated by the model against their empirical counterparts. We calculate real interest rate spreads by correcting the (nominal) forward premia data with realized inflation. Let $f p_{t+1}^{f, U S A}$ be the log forward premia between country $f$ and the United States between $t$ to $t+1$ and $i n f_{t+1}^{f}$ be the log change in the CPI of country $f$ between time $t$ and $t+1$. Then, the real interest rate spread is given by

$$
f p_{t+1}^{f, U S A}-i n f_{t+1}^{f}+i n f_{t+1}^{U S A}
$$

The regression line has a slope of 0.002 and an $R^{2}$ of 0.47 . 


\section{A Equilibrium Consumption of Inactive Households}

Inactive households in country $n$ maximize utility, defined in equation (1), in each state of the world by splitting their wealth $\exp \left(-\mu_{t}^{n}\right) P_{t}^{n} C_{s s}$ optimally between tradable and non-tradable goods. Their optimization problem can be written as maximizing (1) in each state subject to (2) and (6)

$$
\begin{aligned}
\max _{\hat{I}_{T, t}(i), \hat{I}_{N, t}(i)} & \frac{1}{1-\gamma}\left(\tau \hat{I}_{T, t}(i)^{\alpha}+(1-\tau) \hat{I}_{N, t}(i)^{\alpha}\right)^{\frac{1-\gamma}{\alpha}} \\
\text { s.t. } & \hat{I}_{T, t}(i)+P_{N, t} \hat{I}_{N, t}(i)=\exp \left(-\mu_{t}^{n}\right) P_{t}^{n} C_{s s}
\end{aligned}
$$

We solve this problem by setting up a Lagrangian and taking first-order conditions with respect to $I_{T, t}(i)$ and $I_{N, t}(i)$ to get equation $(12)$.

\section{B Social Planner's Problem}

The Social Planner maximizes the utility of active households, subject to the equilibrium behavior of inactive households, the resource constraint for tradable goods, the resource constraint for non-tradable goods and the resource constraint for final goods.

First, we derive the resource constraint for final goods. Final goods are produced by active and inactive households. Final goods are either consumed by inactive households, consumed by active households or used for investment. Hence, the resource constraint for final goods (9) can be written as

$$
\begin{gathered}
\phi\left[\tau\left(I_{T, t}^{n}\right)^{\alpha}+(1-\tau)\left(I_{N, t}^{n}\right)^{\alpha}\right]^{\frac{1}{\alpha}}+(1-\phi)\left[\tau\left(\hat{I}_{T, t}^{n}\right)^{\alpha}+(1-\tau)\left(\hat{I}_{N, t}^{n}\right)^{\alpha}\right]^{\frac{1}{\alpha}}= \\
\phi C_{t}^{n}+(1-\phi) \hat{C}_{t}^{n}+I_{K, t}^{n} .
\end{gathered}
$$

Inactive households optimize their utility by consuming their entire production

$$
\left[\tau\left(\hat{I}_{T, t}^{n}\right)^{\alpha}+(1-\tau)\left(\hat{I}_{N, t}^{n}\right)^{\alpha}\right]^{\frac{1}{\alpha}}=\hat{C}_{t}^{n}
$$

Plugging inactive households' consumption into the resource constraint for the final good 
(31) delivers

$$
\theta^{n}\left(\phi C_{t}^{n}+\left(K_{t+1}^{n}-(1-\delta) K_{t}^{n}\right)\right)=\phi \theta^{n}\left[\tau\left(I_{T, t}^{n}\right)^{\alpha}+(1-\tau)\left(I_{N, t}^{n}\right)^{\alpha}\right]^{\frac{1}{\alpha}} \forall n
$$

The resource constraint for the non-tradable good $(10)$ can be written as

$$
\theta^{n}\left(\phi I_{N, t}^{n}+(1-\phi) \hat{I}_{N, t}^{n}\right)=\theta^{n}\left[\exp \left(\eta_{t}^{n}\right)\left(K_{t}^{n}\right)^{\nu}\right] \quad \forall n
$$

and the resource constraint for the tradable good $(11)$ can be written as

$$
\theta^{n}\left(\phi I_{T, t}^{n}+(1-\phi) \hat{I}_{T, t}^{n}\right)=\theta^{n} Y_{T, t}^{n}
$$

The Social Planner maximizes the utility of active households subject to the resource constraints (32), (33) and (34). We can thus write the Social Planner's value function as

$$
\begin{aligned}
V\left(\left\{K_{t}^{n}, Y_{Y, t}^{n}, \eta_{t}^{n}, \mu_{t}^{n}\right\}_{n=1}^{N}\right) & =\sum_{n} \frac{\phi \theta^{n}}{1-\gamma}\left(C_{t}^{n}\right)^{1-\gamma}+\beta \mathbb{E}\left[V\left(\left\{K_{t+1}^{n}, Y_{Y, t+1}^{n}, \eta_{t+1}^{n}, \mu_{t+1}^{n}\right\}_{n=1}^{N}\right)\right] \\
& +\Lambda_{T, t} \sum_{n} \theta^{n}\left[Y_{T, t}^{n}-\phi I_{T, t}^{n}-(1-\phi) \hat{I}_{T, t}^{n}\right] \\
& +\sum_{n} \Lambda_{N, t}^{n} \theta^{n}\left[\exp \left(\eta_{t}^{n}\right)\left(K_{t}^{n}\right)^{\nu}-\phi I_{N, t}^{n}-(1-\phi) \hat{I}_{N, t}^{n}\right] \\
& +\sum_{n} \Lambda_{t}^{n} \phi \theta^{n}\left(\left[\tau\left(I_{T, t}^{n}\right)^{\alpha}+(1-\tau)\left(I_{N, t}^{n}\right)^{\alpha}\right]^{\frac{1}{\alpha}}-C_{t}^{n}-\frac{1}{\phi}\left(K_{t+1}^{n}-(1-\delta) K_{t}^{n}\right)\right) .
\end{aligned}
$$

The first-order conditions with respect to $I_{T, t}^{n}$ and $I_{N, t}^{n}$ are given by (14) and (15), respectively. The first-order conditions with respect to next period's capital per capita $\left(K_{t+1}^{n}\right)$ is

$$
\theta^{n}\left(C_{t}^{n}\right)^{-\gamma}=\beta \mathbb{E}\left[\frac{\partial}{\partial K_{t+1}^{n}} V\left(\left\{K_{t+1}^{n}, Y_{Y, t+1}^{n}, \eta_{t+1}^{n}, \mu_{t+1}^{n}\right\}_{n=1}^{N}\right)\right]
$$

The envelope condition is

$$
\frac{\partial}{\partial K_{t}^{n}} V\left(\left\{K_{t}^{n}, Y_{Y, t}^{n}, \eta_{t}^{n}, \mu_{t}^{n}\right\}_{n=1}^{N}\right)=\theta^{n}(1-\delta)\left(C_{t}^{n}\right)^{-\gamma}+\Lambda_{N, t}^{n} \theta^{n} \exp \left(\eta_{t}^{n}\right) \nu\left(K_{t}^{n}\right)^{\nu-1}
$$




\section{Log-linearized System of Equations}

We log-linearize the system of equilibrium conditions around the point at which $\sigma_{N, t}^{n}, \tilde{\sigma}_{n}=$ $0 \forall n$. Therefore, we start with equation (14) which leads to

$$
(1-\gamma-\alpha)\left(\tau i_{T}^{n}+(1-\tau) i_{N}^{n}\right)+\log \tau+(\alpha-1) i_{T}^{n}=\lambda_{T} \forall n
$$

and equation (15) yields

$$
(1-\gamma-\alpha)\left(\tau i_{T}^{n}+(1-\tau) i_{N}^{n}\right)+\log (1-\tau)+(\alpha-1) i_{N}^{n}=\lambda_{N}^{n} \forall n
$$

Next we approximate the resource constraint for non-tradable goods 33 in which we substitute equilibrium consumption of inactive households $(12)$ and replace prices $P_{N, t}$ and $P_{t}$ with the ratio of Lagrange multipliers from 13 .

$$
\phi i_{N}^{n}+(1-\phi)\left(-\mu^{n}-\tau \frac{1}{1-\alpha}\left(\left(\lambda_{N}^{n}-\lambda_{T}\right)-\log \left(\frac{1-\tau}{\tau}\right)\right)\right)=y_{N}^{n} \forall n
$$

Lastly, we sum the resource constraint for tradable goods (33) over all countries and again substitute for the consumption of inactive households and prices as above to get

$\phi \sum_{n=1}^{N} \theta^{n} i_{T}^{n}+(1-\phi) \sum_{n=1}^{N}\left(-\mu^{n}+\frac{1}{1-\alpha}(1-\tau)\left(\left(\lambda_{N}^{n}-\lambda_{T}\right)-\log \left(\frac{1-\tau}{\tau}\right)\right)\right)=\sum_{n=1}^{N} \theta^{n} y_{T}^{n}$

\section{Proof for Proposition 2}

When financial markets are incomplete, $Y_{N, 1}^{n} \neq C_{N, 1}^{n}$. Hence, we can no longer use $\Lambda_{N, 1}^{n} Y_{N, 1}^{n}=(1-\tau)\left(\Lambda_{1}^{n}\right)^{1-\frac{1}{\gamma}}$. Instead, differences in two countries' per capita capital stocks can be written as

$$
k_{1}^{f}-k_{1}^{h}=\mathbb{E}\left[\lambda_{N, 1}^{f}+y_{N, 1}^{f}-\lambda_{N, 1}^{h}-y_{N, 1}^{h}\right]+\frac{1}{2}\left(\operatorname{var}\left(\lambda_{N, 1}^{f}+y_{N, 1}^{f}\right)-\operatorname{var}\left(\lambda_{N, 1}^{h}+y_{N, 1}^{h}\right)\right)
$$


If the economy is only affected by inflation shocks, the marginal utility of non-tradable consumption of households in country $n$ is

$$
\lambda_{N}^{n}=-\frac{(1-\phi)(\gamma-\phi) \gamma \tau}{\phi(\gamma \tau+(1-\tau) \phi)} \bar{\mu}-\frac{(1-\phi) \gamma}{\gamma \tau+(1-\tau) \phi} \mu^{n}+\log [1-\tau]
$$

It follows that $\mathbb{E}\left[\lambda_{N, 1}^{n}\right]=\log [1-\tau]$ and $\operatorname{cov}\left(\lambda_{N, 1}^{n}, y_{N, 1}^{n}\right)=0$ for all $n$. Hence,

$$
k_{1}^{f}-k_{1}^{h}=\frac{1}{2}\left(\operatorname{var}\left(\lambda_{N, 1}^{f}\right)-\operatorname{var}\left(\lambda_{N, 1}^{h}\right)\right)
$$

Differential incentives to accumulate capital arise from the difference in the volatility of marginal utilities of the two countries. These result from differences in $\operatorname{cov}\left(\bar{\mu}, \mu^{n}\right)$ and from differences in the volatility of $\mu^{n}$.

\section{E Differential Incentives for Capital Accumulation}

When markets are incomplete and the economy is affected by both real and monetary shocks the differential incentive to accumulate capital can be written as

$$
\begin{aligned}
k_{1}^{f}-k_{1}^{k}= & \frac{\gamma^{2}(1-\phi)^{2}}{2(\gamma \tau+(1-\tau) \phi)^{2}}\left(\tilde{\sigma}_{f}^{2}-\tilde{\sigma}_{h}^{2}\right)+\frac{\gamma^{2}(1-\phi)^{2} \tau(\gamma-\phi)}{\phi(\gamma \tau+(1-\tau) \phi)}\left(\theta^{f} \tilde{\sigma}_{f}^{2}-\theta^{h} \tilde{\sigma}_{h}^{2}\right)+ \\
& \frac{\phi(\gamma-\phi)^{2}(1-\tau)^{2}}{2(\gamma \tau+(1-\tau) \phi)^{2}}\left(\sigma_{N, f}^{2}-\sigma_{N, h}^{2}\right)+\frac{(1-\tau)^{2} \tau(\gamma-\phi)^{3}}{\phi(\gamma \tau+(1-\tau) \phi)}\left(\theta^{f} \sigma_{N, f}^{2}-\theta^{h} \sigma_{N, h}^{2}\right)
\end{aligned}
$$

The expression $k_{1}^{f}-k_{1}^{h}$ is unambiguously greater than zero if country $f$ is more systemic than country $h$.

\section{F Data Appendix}

\section{F.1 Data Sources}

IMF Exchange Rate Class The IMF exchange rate regime classification was taken from the data section of Carmen Reinhart's website. 
Nominal Exchange Rates Nominal exchange rates are taken from the National Accounts section of the OECD Statistics database. The exchanges rates are given as quarterly averages of national currency per US dollar.

Consumer Price Index We use a CPI deflator to translate nominal exchange rates to real exchange rates. We use the "Consumer prices - all items" variable from the Consumer Prices (MEI) subsection of the Prices and Purchasing Power Parities section of the OECD Statistics database. The base year for the CPI is 2010.

Real GDP (OECD) We use GDP data to generate each country's Pareto weights. These data come from the OECD Statistics database. Real GDP is measured using the expenditure approach at the annual frequency, in millions of national currency, in the OECD reference year prices, and are seasonally adjusted.

Real GDP per Capita We also gather real GDP per capita data to calculate the standard deviation of the growth rate of real GDP per capita. The data are GDP per head of population measured in USD, constant prices at 2005 PPPs. They are taken from the OECD Statistics database under the subject heading T_GDPPOP.

Capital Stock Capital stock data is taken from the Penn World Tables version 8.1. We use "Capital stock at constant 2005 national prices (in mil. 2005US\$)". The data can be accessed at:

http://citaotest01.housing.rug.nl/FebPwt/Dmn/AggregateXs.mvc/VariableCodeSelect. The capital stock data are given at the annual frequency.

Real GDP (PWT) We use the Penn World Table's version of real GDP as the denominator for calculating capital-output ratios across countries. This is "Real GDP at constant 2005 national prices (in mil. 2005US\$)". As with the capital stock data, these data are given at the annual frequency.

Population We use population data to generate a measure of consumption growth per capita. We use the variable "Population (hist5) All ages" from the OECD Statistics database. Population data are given at the annual frequency.

Consumption Growth We obtain consumption growth data from the OECD Statistics database. We observe net GDP private final consumption expenditure growth from the previous period as a percentage. The subject code is NAEXKP02.

Forward Premia Data In order to calculate differences in real bond returns, we use 
forward premia data from Hassan and Mano (2015). Under covered interest parity, the $\log$ forward premia between two countries is equal to the spread in the two countries' log risk free bond returns.

\section{F.2 Moment Generation}

We estimate our model using the following moments

1. The variance of each each country's average real exchange rate normalized by the average variance of the average real exchange rates across countries

2. The variance of each each country's average nominal exchange rate normalized by the average variance of the average nominal exchange rates across countries

3. The average variance of per capita GDP growth

4. The average variance of inflation

\section{Real Exchange Rates}

We calculate the real exchange rate between each pair of countries by adjusting their nominal exchange rate by the ratio of their CPIs. Specifically, this is

$$
R E R_{t}^{h, f}=N E R_{t}^{h, f} \frac{C P I^{f}}{C P I^{h}}
$$

where $R E R_{t}^{h, f}$ is the real exchange rate given as the amount of currency $h$ needed to buy a unit of currency $f, N E R_{t}^{h, f}$ is the corresponding nominal exchange rate, and $C P I^{h}, C P I^{f}$ are the price indicies for each country.

We calculate each country's average exchange rate as the equally weighted sum of that country's exchange rates appreciations For country $h$, the average exchange rate is

$$
\overline{r e r}_{t}^{h}=\sum_{f \neq h} \frac{1}{N-1}\left[\log R E R_{t+1}^{h, f}-\log R E R_{t}^{h, f}\right]
$$

We calculate the variance of this average real exchange rate, $\operatorname{var}\left(\overline{\operatorname{rer}}_{t}^{h}\right)$. 
We normalize each variance, $\operatorname{var}\left(\overline{\operatorname{rer}}_{t}^{h}\right)$, by the average variance, $\sum_{h} \frac{1}{N} \operatorname{var}\left(\overline{\operatorname{rer}}_{t}^{h}\right)$. This allows us to match the relative volatility of exchange rates without having to match the level of exchange rates.

The theoretical counterpart to the variance of the real exchange rate between countries $h$ and $f$ is

$$
\operatorname{Var}\left(\overline{r e r}^{h}\right)=\operatorname{Var}\left(\sum_{f \neq h} \frac{1}{N-1}\left[p_{t+1}^{h}-p_{t+1}^{f}-\left(p_{t}^{h}-p_{t}^{f}\right)\right]\right)
$$

where $p_{t}^{n}$ represents the log price level of country $n$ in period $t$

\section{Nominal Exchange Rates}

We calculate the variance of average nominal exchange rates in the same way as we calculated the variance of average real exchange rates. For country $h$, this is

$$
\operatorname{var}\left(\overline{n e r}_{t}^{h}\right)=\operatorname{var}\left(\sum_{f \neq h}^{N} \frac{1}{N-1}\left[\log N E R_{t+1}^{h, f}-\log N E R_{t}^{h, f}\right]\right)
$$

The theoretical counterpart to the variance of the average nominal exchange rate between countries $h$ is

$$
\operatorname{var}\left(\overline{\operatorname{ner}}^{h}\right)=\operatorname{var}\left(\sum_{i=1}^{N} \frac{1}{N}\left[-\mu_{t+1}^{h}+\mu_{t+1}^{f}+p_{t+1}^{h}-p_{t+1}^{f}-\left(p_{t}^{h}-p_{t}^{f}\right)\right]\right)
$$

where $\mu_{t}^{n}$ is the inflationary shock in country $n$ at time $t$.

\section{Average Variance of GDP Growth}

We use annual GDP per capita data from the OECD. Call this GDPPC . We calculate the variance of GDP growth for country $n$ by taking the variance of $\log G D P P C_{t+1}^{n}-$ $\log G D P P C_{t}^{n}$. Finally, we average the variance of GDP growth across countries.

The theoretical counterpart to real GDP per capita is the value of all goods produced in that country in period $t$ in terms of the final consumption bundle.

$$
G D P P C_{t}=\frac{Y_{T, t}+P_{N, t} Y_{N, t}}{P_{t}}
$$




\section{Average Variance of Inflation}

We measure inflation as the change in the CPI, $I N F_{t+1}=C P I_{t+1} / C P I_{t}$. We calculate the variance of inflation for country $n$ by taking the variance of $\log I N F_{t+1}^{n}$. Finally, we average the variance of inflation across countries.

The theoretical counterpart to inflation is the change in the nominal price level.

$$
\log I N F_{t}^{n}=-\mu_{t+1}^{n}+p_{t+1}^{n}-p_{t}^{n}
$$

\section{Consumption Growth}

We observe consumption growth at the annual frequency from the OECD Statistics library. We calculate log consumption growth and subtract out log population growth in order to measure per capita log consumption growth. This is

$$
d c_{t+1}=\log \left(\frac{C_{t+1}}{C_{t}}\right)-\log \left(\frac{P O P_{t+1}}{P O P_{t}}\right)
$$

where $d c_{t+1}$ is per capita log consumption growth, $C_{t+1} / C_{t}$ is observed from the OECD data and $P O P_{t+1} / P O P_{t}$ is constructed from the population data.

The theoretical counterpart to log per capita consumption is the weighted sum of consumption by active and inactive households.

$$
c_{t}^{n}=\log \left(\phi C_{t}^{n}+(1-\phi) \hat{C}_{t}^{n}\right)
$$

where $C_{t}^{n}$ is the consumption of active households and $\hat{C}_{t}^{n}$ is the consumption of inactive households.

\section{Real and Nominal Interest Rate}

We use forward premia data from Hassan and Mano (2015) to obtain spreads in nominal risk free bonds. Under covered interest rate parity, the log forward premia between two countries is equal to the spread in the two countries' log (nominal) risk free bond returns. In order to obtain real interest rate spreads, we need to correct for inflationary expectations in each period. We use realized inflation. Let $f p_{t+1}^{f, h}$ be the $\log$ forward 
premia from time $t$ to $t+1$ and let nomint $t_{t}^{f}$ be the nominal interest in country $f$ between time $t$ to $t+1$. Then,

$$
f p_{t+1}^{f, h}=\text { nomint }_{t}^{f}-\text { nomint }_{t}^{h}
$$

Letting $i n f_{t+1}^{f}$ represent the realized inflation rate in country $f$ from $t$ to $t+1$, we can write the real interest rate spread as

$$
f p_{t+1}^{f, h}-i n f_{t}^{f}+i n f_{h}^{f}=n o m i n t_{t}^{f}-n o m i n t_{t}^{h}-i n f_{t}^{f}+i n f_{h}^{f}
$$

The theoretical counterpart to the time $t$ risk free interest rate in country $n$ is the expected return on a bond that pays one unit of country $n$ 's consumption bundle in period $t+1$. The price of this bond is

$$
V_{P, t}^{n}=\mathbb{E}\left[\beta \frac{\Lambda_{T, t+1}}{\Lambda_{T, t}} P_{t+1}^{n}\right]
$$

and the expected return on the risk free bond of country $n$ is

$$
\mathbb{E}\left[\frac{P_{t+1}^{n}}{V_{P, t}^{n}}\right]
$$

\section{Bootstrapped Standard Errors}

We bootstrap standard errors for the average standard deviation of log GDP growth and the average standard deviation of log inflation. We draw (with replacement) 10,000 sample economies from our data. We calculate the appropriate moment on each sample economy and then calculate the standard deviation of the moment across sample economies. 